\title{
Random sub-diffusion and capture of genes by the nuclear pore reduces dynamics and coordinates interchromosomal movement
}

\author{
Michael Chas Sumner ${ }^{1}$, Steven B. Torrisi ${ }^{2}$, Donna Garvey Brickner ${ }^{1}$ and \\ Jason H. Brickner ${ }^{1}$ \\ ${ }^{1}$ Department of Molecular Biosciences, Northwestern University, Evanston, IL USA \\ ${ }^{2}$ Department of Physics, Harvard University, Cambridge MA USA \\ Address correspondence to j-brickner@northwestern.edu
}




\begin{abstract}
Hundreds of genes interact with the yeast nuclear pore complex (NPC), localizing at the nuclear periphery and clustering with co-regulated genes. Dynamic tracking of peripheral genes shows that they cycle on and off the NPC and that interaction with the NPC slows their sub-diffusive movement. Furthermore, NPC-dependent inter-chromosomal clustering leads to coordinated movement of pairs of loci separated by hundreds of nanometers. We developed Fractional Brownian Motion simulations for chromosomal loci in the nucleoplasm and interacting with NPCs. These simulations predict the rate and nature of random sub-diffusion during repositioning from nucleoplasm to periphery and match measurements from two different experimental models, arguing that recruitment to the nuclear periphery is due to random subdiffusion, collision, and capture by NPCs. Finally, the simulations do not lead to interchromosomal clustering or coordinated movement, suggesting that interaction with the NPC is necessary, but not sufficient, to cause clustering.
\end{abstract}




\section{INTRODUCTION}

In eukaryotes, genomes are spatially organized within the nucleus. Chromosomes occupy distinct subnuclear "territories", heterochromatin is segregated from euchromatin, and individual genes show non-random positioning relative to nuclear structures and other genes (Misteli, 2020). Gene positioning reflects physical interactions of chromosomal loci with nuclear structures like the nuclear lamina, nuclear pore complexes or nuclear bodies and changes in gene expression are often accompanied by changes in gene positioning (Brickner, 2017). The positioning of genes can impact their transcription, mRNA processing, or chromatin modifications.

One model for such phenomena is the recruitment of genes to the nuclear periphery through interaction with the nuclear pore complex (NPCs). Hundreds to thousands of genes in budding yeast, $C$. elegans, Drosophila, and mammals physically interact with NPCs, suggesting that the NPC plays an important role in determining the spatial arrangement of eukaryotic genomes (C. R. Brown et al., 2008; Capelson et al., 2010; Casolari et al., 2004, 2005; Ibarra et al., 2016; Jacinto et al., 2015; Liang et al., 2013; Pascual-Garcia et al., 2017; Rohner et al., 2013; Toda et al., 2017). This is particularly apparent in budding yeast, where hundreds of genes interact with the NPC and inducible genes rapidly reposition to the nuclear periphery upon activation (Casolari et al., 2005, 2004; Vosse et al., 2013). Interaction with the NPC and localization to the nuclear periphery require specific transcription factors (TFs) and nuclear pore proteins (Brickner et al., 2019, 2012, 2007; Cabal et al., 2006; Dieppois et al., 2006; Dilworth et al., 2005; D’Urso et al., 2016; Lapetina et al., 2017; Luthra et al., 2007; Randise-Hinchliff et al., 2016; Texari et al., 2013; Vosse et al., 2013). A majority of yeast TFs mediate interaction with the NPC (Brickner et al., 2019), suggesting that the yeast genome encodes spatial organization through cis-acting TF binding sites. Such cis-acting acting DNA zip codes are both necessary and sufficient to mediate interaction with the NPC and positioning to the nuclear periphery (Ahmed et al., 2010; Brickner et al., 2019, 2012; Light et al., 2010; Randise-Hinchliff et al., 
2016). Furthermore, interaction with the NPC frequently leads to inter-chromosomal clustering of co-regulated genes, suggesting that it influences the spatial organization of the yeast genome at multiple levels (Brickner et al., 2016, 2012; Kim et al., 2019, 2017; Mirkin et al., 2013; Randise-Hinchliff et al., 2016).

Much of the work on gene positioning and recruitment to the nuclear periphery has utilized static population measurements such as microscopy, chromatin immunoprecipitation, or $\mathrm{HiC}$. Although these studies have revealed important players necessary for gene positioning to the nuclear periphery, there are questions that cannot be answered using static methods. For example, while some loci interact very stably with the nuclear envelope (e.g., telomeres and centromeres; Heun et al., 2001; Jin et al., 2000), leading to $\sim 85 \%$ of cells showing colocalization of these loci with the nuclear envelope, genes that interact with the NPC show lower levels ( 50-65\%; Brickner and Walter, 2004; Casolari et al., 2004). This has been suggested to reflect transient interaction with the nuclear periphery (Brickner and Walter, 2004), cell-cycle regulation of peripheral localization (Brickner and Brickner, 2010) or, perhaps, two distinct populations, one that stably associates with the NPC and the other that does not (Brickner and Walter, 2004; Cabal et al., 2006). Likewise, the repositioning of genes from the nucleoplasm to the nuclear periphery is not well-understood. Some data - including the involvement of nuclear actin and myosin - has suggested that repositioning to the NPC could be an active, vectorial process (Guet et al., 2015; Wang et al., 2020). Finally, while inter-chromosomal clustering is a widespread phenomenon (Apostolou and Thanos, 2008; Brickner et al., 2012; Brown et al., 2006; Homouz and Kudlicki, 2013; Kim et al., 2017; Lin et al., 2009; Noma et al., 2006; Schoenfelder et al., 2010; Thompson et al., 2003), relatively few studies have explored the dynamics of clustering over time and it is unclear if clustering reflects a stable physical interaction (Brickner et al., 2016; Dai et al., 2018). High-resolution, quantitative dynamics of chromatin diffusion are required to approach each of these questions.

Chromatin is a mobile polymer and individual loci exhibit constrained or anomalous 
diffusion (Bystricky et al., 2004; Gasser, 2002; Hajjoul et al., 2013; Heun et al., 2001; W.F Marshall et al., 1997). Chromatin motion can reveal important aspects of the nuclear environment and the biophysical mechanisms that control the spatial organization of the genome. Targeting to the NPC in budding yeast is an intriguing model for such studies because it is inducible, relatively rapid, controlled by well-understood DNA elements, and induces both a change in position and inter-chromosomal clustering.

Here we show that targeting to the nuclear periphery is continuous and dynamic but uniform within the population, suggesting that, within each cell, targeting to the periphery it is a probabilistic process. Localization at the nuclear periphery correlates with more constrained diffusion, as suggested by previous work (Backlund et al., 2014; Cabal et al., 2006). Using mean squared displacement (MSD) and molecular genetics, we pinpoint this effect to the interaction with the nuclear pore complex. The parameters of sub-diffusion derived from MSD of nucleoplasmic loci were used to develop a computational simulation that faithfully recapitulates the behavior of such genes. This simulation was also adapted to model repositioning to the nuclear periphery through random sub-diffusion and capture at the nuclear envelope. The repositioning predicted by the simulation was then compared with several rapid repositioning experiments to determine if targeting to the NPC is vectorial or super-diffusive. The simulation matched the observed behavior of loci in cells, suggesting that repositioning from the nucleoplasm to the nuclear periphery does not require an active mechanism.

Finally, we monitored the dynamics of inter-chromosomal clustering. Unlike pairs of simulated paths, genes that exhibit clustering remain near each other for tens of seconds and show correlated movement. Simulated interaction with the NPC, while sufficient to recapitulate the chromatin dynamics of individual loci, is not sufficient to recapitulate this correlated movement. Therefore, we propose that inter-chromosomal clustering relies on a distinct physical interaction between genes that can extend hundreds of nanometers. 


\section{RESULTS}

\section{Chromatin targeting to the NPC is continuous and dynamic.}

The localization of genes at the nuclear periphery can be followed in live yeast cells by tagging chromosomal loci of interest with an array of 128 Lac operators in a strain expressing GFP-Lac repressor (GFP-Lacl) and quantifying its colocalization with mCherry-marked nuclear envelope (Figure 1A; Brickner and Walter, 2004; Egecioglu et al., 2014; Robinett et al., 1996; Straight et al., 1996). In static confocal microscopy experiments, repositioning of inducible genes such as HIS4 or INO1 to the periphery leads to an increase in the fraction of cells in which the locus colocalizes with the nuclear envelope from that expected for a random distribution ( 30\%) to 50-65\% (Figure 1B \& D; Brickner and Walter, 2004; Egecioglu et al., 2014). However, artificially tethering chromatin to the nuclear envelope leads to $\sim 85 \%$ colocalization with the nuclear envelope (Brickner and Walter, 2004). This suggests that localization to the nuclear periphery reflects either dynamic and continuous targeting to the NPC or two distinct populations of cells, one that exhibits stable association with the nuclear envelope and the other that does not. To distinguish between these possibilities, we quantified peripheral localization of three LacO-tagged loci over time in individual cells: the inducible genes HIS4 and INO1, as well as the negative control URA3, which localizes in the nucleoplasm (Figure 1B \& D; Brickner et al., 2019; Brickner and Walter, 2004; Randise-Hinchliff et al., 2016). To avoid the complication that targeting of many genes to the NPC is lost during S-phase (Brickner and Brickner, 2010), cells were synchronized using nocodazole and released into G1 for 30 minutes before scoring colocalization with the nuclear envelope every 10 s over 10 minutes. In complete media (i.e., uninducing conditions), all three genes showed similar patterns: episodic, brief colocalization with the nuclear envelope (Figure 1C, E \& F). However, under inducing conditions (-histidine for HIS4 or -inositol for INO1), the pattern changed. Both HIS4 and INO1 showed longer periods of colocalization with the nuclear envelope (Figure 1C, F \& J), while URA3 was unaffected (Figure 1E). The pattern was consistent across the population 
and the fraction of cells in which HIS4 or INO1 colocalized with the nuclear envelope at each time point (Figure $1 \mathrm{H})$ was in close agreement with the fraction of time spent colocalized with the nuclear envelope in each cell (Figure 1I). This argues against two distinct populations and instead suggests that targeting to the NPC is continuous and dynamic over time, increasing the duration of colocalization with the nuclear envelope.

Targeting to the NPC is mediated by transcription factors binding to cis-acting elements that function as DNA zip codes (Ahmed et al., 2010; Brickner et al., 2019; Light et al., 2010). For example, the Gene Recruitment Sequence GRS1 from the INO1 promoter binds to the Put3 transcription factor to mediate targeting to the NPC (Brickner et al., 2012). Likewise, the Gcn4 binding site (GCN4 BS) from the HIS3 promoter mediates targeting to the NPC (RandiseHinchliff et al., 2016). Such zip codes are both necessary and sufficient to cause peripheral localization; inserting them near URA3 causes repositioning to the nuclear periphery (e.g. URA3:GRS1, Figure 1D; Ahmed et al., 2010; Randise-Hinchliff et al., 2016). The association of URA3:GRS1, which shows unregulated targeting to the periphery, with the nuclear envelope over time resembled that of active HIS4 and INO1 (Figure 1G-J). Thus, DNA zip code-mediated targeting to the NPC is sufficient to produce continuous and dynamic association with the nuclear envelope.

\section{Chromatin sub-diffusion is suppressed by interaction with the nuclear pore complex.}

We next examined how interaction of genes with the NPC impacts the dynamics of diffusion. Chromosomal loci exhibit constrained sub-diffusion, which can be quantified using mean squared displacement analysis (MSD; W.F Marshall et al., 1997). For comparison, we tracked the movement of the less mobile nuclear envelope-embedded spindle pole body (SPB) and a much more mobile cytoplasmic particle (the $\mu$ NS viral capsid; Munder et al., 2016). While $\mu N S$ was highly diffusive, the SPB showed very limited displacement at this time scale, reflecting both slow diffusion within the membrane and movement of the whole nucleus (Figure 
2B). We assessed the MSD of eleven nucleoplasmic loci not associated with the NPC and two telomeres tethered to the nuclear envelope (Figure 2B; Table S1). These loci exhibited a range of intermediate MSD between these two extremes, with the nucleoplasmic loci showing greater mobility than tethered telomeres and telomeres showing greater mobility than the SPB (Figure 2B). Simultaneously acquiring images of chromosomal loci and the SPB to correct for nuclear movement significantly reduced the time resolution. Given that nuclear movement was much less than chromosomal movement at these time scales, it could be ignored. We also determined the MSD of chromosomal loci in 3D. Although this gave very similar results (Table $\mathrm{S1})$, the quality of the data was lower because of the longer time interval (>1s). For these reasons, we limited our movies for MSD analysis to 40 s at $210 \mathrm{~ms}$ resolution $(200 \times 0.21 \mathrm{~s})$ in a single focal plane and calculated MSD for time intervals up to 4s (Figure 2B).

The nucleoplasmic loci showed a range of mobility by MSD, perhaps reflecting nearby physical interactions with the nuclear envelope. Indeed, the initial mean squared displacements $(\tau=0.21 \mathrm{~s})$ correlated with the distance to the nearest nuclear envelope tethering point (either centromeres or telomeres; MSD $\sim \log _{10}(\mathrm{bp}) ; R^{2}=0.65$; Figure $\left.2 \mathrm{C}\right)$. Thus, diffusion of chromatin is influenced over a range of distances by stable interactions with the nuclear envelope (Hediger et al., 2006; Hediger and Gasser, 2002), complicating direct comparison of MSD between loci.

To quantify the effect of local interaction with the NPC on chromatin sub-diffusion and to avoid this complication, we exploited genes that show conditional association with the NPC. We compared the MSD of INO1, HIS4 and URA3 under either uninducing and inducing conditions ( \pm histidine and \pm inositol). URA3 showed no change in MSD under these conditions (Figure 2D). However, both HIS4 and INO1 showed significantly reduced mobility upon induction (Figure 2E \& F), confirming that repositioning to the nuclear periphery correlates with reduced chromatin sub-diffusion.

Shifting cells to the inducing conditions leads to both repositioning to the nuclear periphery and transcriptional activation. The change in MSD of INO1 and HIS4 could be due to 
the effects of transcription, the interaction with the NPC, or both. To distinguish the effects of transcription from the effects of interaction with the NPC, we also measured the effect of DNA zip codes on the MSD of URA3. Single copies of zip codes from the promoters of INO1 (URA3:GRS1; Figure 3A) or HIS4 (URA3:Gcn4 BS; Figure 3B) were integrated beside URA3. These elements promote interaction with the NPC outside the context of a transcribed promoter. URA3:GRS1 is targeted to the nuclear periphery constitutively (Figures 1D \& 3A; Ahmed et al., 2010; Randise-Hinchliff et al., 2016), resulting in a reduced MSD under all conditions (Figure 3A). In contrast, URA3:GCN4BS shows conditional targeting to the NPC upon amino acid starvation (Figure 3B, inset; Randise-Hinchliff et al., 2016), and a conditional reduction in MSD (Figure 3B). Loss of the NPC protein Nup2 disrupts DNA zip code-mediated targeting to the nuclear periphery and resulted in MSD similar to URA3 under all conditions (Figure 3C \& D). Thus, DNA zip code-mediated interaction with the NPC is sufficient to suppress chromatin subdiffusion.

Finally, we exploited loss of trans-acting transcriptional regulators of the INO1 gene to disentangle peripheral localization from transcriptional activity. INO1 targeting to the NPC is regulated by the Opi1 repressor, which recruits the Rpd3L histone deacetylase, regulating binding of the Put3 transcription factor to the GRS1 zip code (Randise-Hinchliff et al., 2016). Because Opi1 is recruited to the INO1 promoter by binding to the Ino2 activator (Heyken et al., 2005), loss of either Ino2 or Opi1 leads to constitutive peripheral localization (Figure 3 E \& F, insets; Randise-Hinchliff et al., 2016). However, these two mutants have opposite effects on INO1 transcription: ino2 $\Delta$ blocks all expression, while opi1 $\Delta$ shows unregulated, high-level expression (Greenberg et al., 1982a, 1982b). In both mutants, the INO1 MSD resembled that of active INO1 (Figure 3E \& F), suggesting that interaction with the NPC is the principal cause of the decrease in sub-diffusion. 


\section{Simulating chromatin sub-diffusion and repositioning to the nuclear periphery}

Using parameters from the MSD analysis, we developed a simulation of chromatin subdiffusion (https://github.com/MCnu/YGRW). Passive sub-diffusion of a segment of chromatin results from forces affecting the chromatin segment both directly (e.g., the viscoelastic potential of the polymer and boundary collision) and indirectly (forces and membrane tethering along distal regions of the same chromatin polymer; Figure 2C). MSD data for a Rouse polymer like chromatin reflects a relationship $\operatorname{MSD}(\tau)=\Gamma\left(\tau^{\alpha}\right)$ for any time interval $\tau$ (Socol et al., 2019).

Gamma $(\Gamma)$ describes the fundamental diffusion coefficient, while an $\alpha$ exponent less than one reflects a hallmark for sub-diffusive movement: each step vector is anti-correlated with both the previous and subsequent steps (Lucas et al., 2014). Published work (Hajjoul et al., 2013) and our MSD data on nucleoplasmic loci (see Materials and Methods), suggests that yeast chromatin has an $\alpha=0.52$. Anti-correlated movement cannot be reproduced through either a random walk or simple process of weighted step sizes derived from our experimental observations (Figure 4 Supplement 1A \& B; uniform and Gaussian, respectively). However, a continuous-time Gaussian process known as Fractional Brownian Motion (FBM) produces trajectories that approximate chromatin sub-diffusion (Lucas et al., 2014). FBM produces nonindependent steps across time, allowing us to impart the anti-correlation between individual steps that is characteristic of chromatin sub-diffusion. For each trajectory, two numeric arrays for the $\mathrm{x}$ and $\mathrm{y}$ dimensions of movement (Dietrich and Newsam, 1997) were generated based on an expected covariance matrix and the $\alpha=0.52$. This array produces a stochastic time series of vectors with an anti-correlation structure functionally identical to that observed for chromatin movement. Finally, these vectors were scaled according to the experimentally derived $\Gamma$ value and Hurst exponent ( $\alpha / 2$; Mandelbrot and Ness, 1968). Starting from random positions within the nucleus, the resulting array of discrete step lengths describes a single, twodimensional sub-diffusive particle trajectory. This simple and rapid approach generates 
trajectories similar to our experimental observations and impart memory that closely resembles the MSD of chromosomal loci in the nucleoplasm (Figure 4 - Figure Supplement $1 A \& B$ ).

Paths generated by FBM suffer from one significant shortcoming. In an enclosed volume, FBM will deplete occupancy of particles near the boundary over time, resulting in a biased distribution (Figure 4 -Figure supplement 1C). This phenomenon has also been reported by others (Vojta et al., 2020) and is not consistent with observations that chromosomal loci, unless associated with the nuclear envelope, localize at the nuclear periphery at a frequency expected from a random distribution (Brickner and Walter, 2004; Hediger et al., 2002). This may reflect a fundamental difference between sub-diffusion of particles and the apparent subdiffusion of a segment of chromatin. We explored several methods to avoid depletion at the nuclear periphery and found that the following was effective: steps that would have taken the locus beyond the boundary were replaced with steps to the boundary along the same vector and, upon interaction with the boundary, the normalized, correlated noise for future steps was regenerated (Figure 4A; Figure 4 -Figure supplement 1, FBM + regeneration). This modified simulation produced paths that closely matched the MSD, distribution of positions within the nucleus, and peripheral occupancy of nucleoplasmic chromosomal loci (Figure 4B, E-G).

Based on our model for nucleoplasmic gene movement, we also sought to simulate chromatin interaction with NPCs at the nuclear membrane. Based on the height of the NPC basket (Yang et al. 1998; Vallotton et al., 2019), we created a zone 50nm from the boundary where chromatin could become "bound", causing it to switch to SPB-like sub-diffusion. The probability of binding and unbinding within this zone were defined independently. We optimized the combination of binding and unbinding probabilities between 0.5 and 0.99 by comparing each simulation with the MSD and peripheral occupancy of URA3:GRS1 (Figure 4 - Figure supplement 2). Based on this optimization, we found that a binding probability of 0.9 and a probability of remaining bound of 0.95 resulted in a positional distribution (Figure 4D), peripheral occupancy over time (Figure 4E \& F), and MSD (Figure 4G) that most closely matched that of 
URA3:GRS1. We refer to this modified simulation as simulation + zip code. The fit of the simulation to the mean MSD for URA3 and of the simulation + zip code to the mean MSD for URA3:GRS1 was excellent (Pearson's $X^{2}$ sums of 0.001 and 0.003 , respectively, for $\tau$ from 0.21 - 4s). Together, these two relatively simple simulations capture important aspects of chromatin sub-diffusion and gene positioning at the nuclear periphery.

\section{Chromatin repositioning is achieved by random sub-diffusion and capture}

Chromosomal loci can undergo long-range, directed movement (Miné-Hattab and Rothstein, 2013), raising the possibility that repositioning from the nucleoplasm to the nuclear periphery could be an active process. To explore this question, we first determined the behavior of the simulation, which does not possess active, vectorial movement. Initiating the default simulation of chromatin movement and the simulation + zip code from random positions within the nucleus, we followed the percent of the population showing localization within 150nm of the nuclear edge over time. As expected, the random initial positions resulted in $\sim 28 \%$ peripheral localization (Figure 5A). For the nucleoplasmic simulation, this was unchanged over time. However, the simulation + zip code resulted in stable repositioning to the nuclear periphery within $\sim 2$ minutes (Figure 5A). Therefore, rapid repositioning to the nuclear periphery can occur without any directed, active movement.

To compare these simulations to experimental results, we applied live-cell tracking during repositioning from the nucleoplasm to the periphery. One challenge with such experiments is that the time required for genes to reposition when cells are shifted from uninducing to inducing conditions is gene-specific and can be quite slow (e.g., $t_{1 / 2} \sim 30 \mathrm{~min}$; Brickner et al., 2012, 2007; Randise-Hinchliff et al., 2016). This suggests that the rate-limiting step for repositioning often reflects the regulation of transcription factors that mediate repositioning, rather than the rate-limiting step for movement to the periphery (Randise-Hinchliff et al., 2016). To overcome this complication, we developed two approaches to maximize the 
rate of repositioning from the nucleoplasm to the nuclear periphery. First, we arrested cells bearing URA3:GRS1-LacO with $\alpha$-factor mating pheromone, which disrupts peripheral localization by inhibiting Cdk, which phosphorylates Nup1 and is required for peripheral targeting (Brickner and Brickner, 2010). Upon release from $\alpha$-factor arrest, URA3:GRS1 repositioned to the nuclear periphery within $\sim 15$ minutes (Figure $5 \mathrm{C}$ ).

As a complementary approach, we used an optogenetic switch to recruit URA3 to the nuclear periphery. Tethering of a 27 amino acid "positioning domain" from the Gcn4 transcription factor $\left(\mathrm{PD}_{\mathrm{GCN}}\right.$ ) near URA3 using the LexA DNA binding domain (DBD) is sufficient to target URA3:LexABS to the nuclear periphery (Brickner et al., 2019). Cryptochrome 2 (CRY2) and Cryptochrome Interacting protein CIB1 from $A$. thaliana undergo rapid dimerization when exposed to 488nm light (Benedetti et al., 2018). In a strain having both the LacO array and the LexA binding site at URA3, CRY2-LexA DBD was co-expressed with CIB1-PD $\mathrm{GCN}_{4}$ to generate a light-induced peripheral targeting system (Figure 5D; Brickner et al., 2019). LexA DBD-Gcn4 served as a positive control and a mutant $\mathrm{CIB1}-\mathrm{pd}_{\mathrm{GCN} 4}$ that is defective for peripheral targeting served as a negative control. Cells were arrested, synchronized in G1 and illuminated with $488 \mathrm{~nm}$ light for $1 \mathrm{~s}$ pulses every 10 s over 10 minutes. Illumination resulted in rapid, $\mathrm{PD}_{\mathrm{GCN}_{4}}{ }^{-}$ dependent repositioning to the nuclear periphery within $\sim 7.5$ minutes (Figure $5 E$ ). Thus, both the biological and the opto-genetic stimuli led to rapid repositioning to the nuclear periphery with kinetics comparable to the simulation.

Having established that these two approaches lead to rapid peripheral localization, we then used particle tracking to define the nature of the movement during this transition. URA3, URA3:GRS1 or URA3:LexABS were tracked for 5 minutes at 0.5 s resolution (600 frames) during repositioning. For each movie, the position and time of initial colocalization with the nuclear envelope was recorded (if observed). While peripheral colocalization of URA3:GRS1 and URA3:LexABS + CIB1-PD $\mathrm{GCN}_{4}$ represents - at least some of the time - interaction with the 
NPC, peripheral colocalization of the negative controls does not. Therefore, we expected that if an active process directs genes to the nuclear periphery, the positive and negative controls should show differences in the step velocities, time of arrival or directness of the path preceding arrival at the nuclear periphery. For comparison, we also determined each of these parameters for paths generated by the default simulation and the simulation + zip code, which include no directed movement. The mean velocities for the simulations and experimental controls were statistically indistinguishable, ranging from $0.163 \pm 0.10 \mu \mathrm{m} \mathrm{s}^{-1}$ to $0.207 \pm 0.13 \mu \mathrm{m} \mathrm{s}^{-1}$ (Figure $5 F ; n=6077-9724$ steps per strain), suggesting that the speed of movement was not increased during peripheral targeting. We did not observe significantly more large steps in the experimental movies than in the negative control movies (Figure 5F). The mean arrival time prior to initial contact with the nuclear envelope was also similar between the simulations and the experimental movies, ranging from $105 \pm 49$ s to $133 \pm 54$ s (Figure $5 G$; $n=27$ - 40 cells per strain), consistent with the predictions from the simulation. Finally, to assess if any of the loci underwent processive, vectorial movement during translocation, we measured the radial deviation $(\theta)$ of each step from a direct path to the ultimate contact point at the nuclear envelope (Figure $5 \mathrm{H}$ ). Random sub-diffusion should produce an average $\theta$ of $\sim \pi / 2=1.57$ radians, while directed movement would produce an average of 0 . The simulations were close to random and, while the experimental loci appear slightly more directed than random, the positive and negative controls were indistinguishable (Figure 5I). Taken together, these results indicate that repositioning of chromatin from the nucleoplasm to the nuclear periphery is likely a passive process that relies on random sub-diffusion and collision with the NPC.

\section{Dynamics of inter-chromosomal clustering}

Genes that are targeted to the yeast NPC can exhibit inter-allelic or inter-genic clustering with genes that are targeted to the NPC by the same transcription factor (Brickner et al., 2015, 
2019, 2016, 2012; Kim et al., 2019, 2017; Randise-Hinchliff et al., 2016). Loss of nuclear pore proteins or transcription factors that bind to DNA zip codes disrupts clustering (Brickner et al., 2012). Clustering has been observed using microscopy as a significant shortening of the distances between two loci in the population (Brickner et al., 2012) or using biochemicalgenomics methods such as HiC (Kim et al., 2019, 2017). To explore the dynamics of interchromosomal clustering, we tracked the positions and inter-genic distances of wellcharacterized loci over time in live cells (Figure 6A). Both HIS4 and INO1 show inter-allelic clustering in diploids. Furthermore, inserting DNA zip codes at URA3 induces $\mathrm{x}$ clustering with HIS4 (URA3:GCN4BS; Randise-Hinchliff et al., 2016) and INO1 (URA3:GRS1; Brickner et al., 2012). The URA3 gene, which does not undergo inter-chromosomal clustering (Brickner et al., 2012), and pairs of randomly selected simulated paths served as negative controls.

Similar to snap shots of populations, the distribution of mean distances from each cell over 40 s $(200 \times 0.21 \mathrm{~s})$ revealed clustering of HIS4 with itself as well as inter-genic clustering of HIS4 with URA3:GCN4BS upon histidine starvation (Figure 6B). Likewise, INO1 inter-allelic clustering was observed upon inositol starvation. Mutations in the upstream open reading frames that negatively regulate Gcn4 expression (uORFmt; Mueller et al., 1987; Mueller and Hinnebusch, 1986), led to high-level, constitutive inter-allelic clustering of HIS4 (Figure 6B; Randise-Hinchliff et al., 2016), while loss of Nup2 disrupted all clustering (Figure 6B). Finally, URA3, the simulated nucleoplasmic paths, and the simulated peripheral paths showed no clustering. Thus, NPC- and TF-dependent clustering can be observed over time and the simulated interaction with the NPC is not sufficient to produce clustering.

We also assessed the stability of clustering over time. The lifetimes of clustering (i.e., time two loci remain within 550nm) increased from $\sim 5$ s for unclustered loci to 20-50s upon clustering (Figure 6C). Similarly, the fraction of the total time points in which clustering was observed reflected the strength of clustering (Figure 6D). Because inter-chromosomal clustering persists for relatively long periods of time, it likely reflects a physical interaction. 
Finally, we asked if pairs of loci that exhibit clustering show coordinated movement. To quantify the degree of coordination, we determined both the correlation of step sizes by each locus and the average difference in step angles made by each locus over 40 s movies (200 x 0.21s; Figure 7A \& B). Uncorrelated movement would result in a correlation of step sizes $\sim 0$ and a mean difference of angles of $\sim \pi / 2=1.57$ radians for each movie, while perfectly coordinated movement would show a correlation of step sizes $\sim 1$ and a mean difference of angles of 0 (Figure 7C). Plotting the correlation and the mean difference in angle for many movies against each other gives a scatter plot (Figure 7C-L). As expected, randomly selected pairs of paths generated by the simulation or the simulation + zip code showed no correlated movement (Figure 7D). Likewise, nucleoplasmic URA3 did not show correlated movement with itself (Figure 7- Figure Supplement 1) or with HIS4 (Figure 7J). However, strains that exhibited clustering (i.e., HIS4 v HIS4, HIS4 v URA3:Gcn4BS or INO1 v INO1) showed a different pattern (Figure 7E, G \& K). While the movement of loci that were $>0.55 \mu \mathrm{m}$ (orange dots) was uncorrelated, the subset of loci that were $\leq 0.55 \mu \mathrm{m}$ (purple dots) showed correlated movement, both in terms of step size and angle. We quantified this behavior using the slope and $R^{2}$ of the scatter plots (Figure 7). Unclustered control loci gave slopes $\sim 0$ and $R^{2} \leq 0.1$ (e.g., Figure 7D \& J). Under inducing conditions (but not under non-inducing conditions), clustered loci showed a slope closer to the ideal -1.57 and $R^{2} \geq 0.65$ (Figure 7E, G \& K). Furthermore, overexpression of Gcn4 (uORFmt), led to constitutive, highly coordinated movement (Figure $7 \mathrm{H})$. Finally, loss of Nup2 disrupted coordinated movement (Figure 7F, I \& L). Thus, targeting to the nuclear pore complex, while not sufficient to cause clustering, is required for clustering and coordinated movement. These results indicate that chromosomal loci separated by hundreds of nanometers physically influence each other at a distance. 


\section{DISCUSSION}

Tracking yeast NPC-associated chromatin over time revealed frequent exchange between the nucleoplasm and periphery (Figure 1), suggesting that the interaction with the NPC is continuously re-established and that the population averages reflect this dynamism, rather than distinct, stable subpopulations. In other words, localization to the nuclear periphery is less well described as tethering than as a change in the steady-state positioning through continuous binding and dissociation. As interaction with the NPC enhances transcription (Ahmed et al., 2010; Brickner et al., 2019, 2016, 2012; Capelson et al., 2010; Jacinto et al., 2015; Liang et al., 2013; Pascual-Garcia et al., 2014; Taddei et al., 2006), it is intriguing that the periodic and transient interaction with the NPC is reminiscent of the widespread phenomenon of transcriptional "bursting" (Femino et al., 1998; Rodriguez and Larson, 2020). Transcriptional bursting leads to heterogeneity in the transcription between cells within a population (Zenklusen et al., 2008) and disrupting the interaction of the GAL1-10 promoter with the NPC leads to a decrease in the number of cells expressing these genes without affecting the amount of transcript produced at the site of transcription (Brickner et al., 2016). Perhaps interaction with the yeast NPC functions with other transcriptional regulators to simulate transcriptional bursts. Exploring this connection will require assessing the dynamics of chromatin positioning and transcription simultaneously in live cells.

Chromatin undergoes anomalous sub-diffusive movement during interphase (Hajjoul et al., 2013; W. F. Marshall et al., 1997). The physical interaction between chromatin and the NPC, though transient, reduces chromatin sub-diffusion (Figure 2; Backlund et al., 2014; Cabal et al., 2006), independent of changes in transcription (Figures $2 \& 3$ ). Using the parameters derived from MSD, we developed computational simulations for yeast chromatin sub-diffusion in the nucleoplasm and at the nuclear periphery. The exponent $\alpha-0.52$ for yeast chromatin (Hajjoul et al., 2013) - reflects anticorrelation between successive steps and can be modeled as fractional Brownian motion (FBM, a.k.a. overdamped fractional Langevin motion; Lucas et al., 
2014). Sub-diffusion of yeast chromosomal loci is determined by the elastic response from the chromatin polymer and the viscous interaction between the polymer and the nucleoplasm.

While we do not explicitly simulate the total chromatin polymer or other nuclear occupants, FBM captures their net effects, recapitulating the MSD behavior of a nucleoplasmic locus (Figure 4). However, the FBM model leads to exclusion near boundaries, leading to non-random positioning of loci, a phenomenon that is not consistent with experimental observations. This likely reflects the fact that, while the motion of a segment of chromatin can be modeled as an FBM particle, it is part of a polymer and is not an FBM particle. Our solution to this shortcoming of the FBM model, allowing collisions with the nuclear periphery to reset the calculated path (see detailed explanation in Methods), produced localization patterns and MSD behaviors that are consistent with experimental observations. However, additional theoretical and experimental work will help clarify the biological and physical significance of this modification.

To simulate the interaction of chromatin with the NPC, we allowed loci in an area within $50 \mathrm{~nm}$ of the nuclear boundary to "bind" to the nuclear periphery, assuming the mobility of the SPB. The width of this annulus is roughly equal to the height of the NPC nuclear basket (Vallotton et al., 2019), whose components are required for chromatin association with the NPC (Ahmed et al., 2010). We independently optimized the probability of binding and of remaining bound by comparing the positioning and MSD of simulated paths with that conferred by a DNA zip code. This simple modification of the simulation was able to reliably recreate the peripheral localization and constraint on chromatin sub-diffusion caused by interaction with the NPC (Figure 4). Thus, the work described here provides a straight-forward and powerful theoretical framework for modeling the biophysical nature of gene positioning through associating with any stable nuclear structure.

Recruitment of genes to the NPC during transcriptional activation occurs over a wide range of time scales, depending on the stimulus and target gene (Randise-Hinchliff et al., 2016), making it difficult to establish if it represents active or vectorial movement. Our simulated 
trajectories offer an important insight; starting from random positions within the center of the yeast nucleus, individual loci reached the nuclear periphery within $\sim 2$ minutes by random subdiffusion (Figure 5G). Allowing interaction with the NPC led to a shift in the localization of loci to the periphery within the population on a similar time scale (Figure $5 \mathrm{~A}$ ). This time scale is comparable to the experimental models for NPC targeting (Figure 5), arguing that active mechanism(s) are unnecessary to explain the observed rate of repositioning. More importantly, experimental analysis of the speed and vector of individual steps preceding contact with the nuclear envelope showed non-vectorial sub-diffusive movement that was indistinguishable from that captured by the simulation (Figure 5). Importantly, there was also no difference between experimental cells and negative control cells for these components. These results indicate that zip code-dependent gene localization results from stochastic, sub-diffusive chromatin movement, random collision with the NPC, leading to dynamic binding. The recently discovered role for actin and Myo3 in targeting of INO1 to the NPC (Wang et al., 2020), raises an important question: how do these factors impact peripheral targeting through a sub-diffusive mechanism? Perhaps, like actin (Kapoor et al., 2013), Myo3 impacts the function of chromatin remodeling complexes or histone modifying enzymes, which regulate binding of transcription factors to DNA zip codes (Randise-Hinchliff et al., 2016). Alternatively, perhaps actin/Myo3 act at the NPC to facilitate capture. A better biochemical and biophysical understanding of these processes will illuminate such possible roles.

Interaction with nuclear pore proteins plays a conserved role in promoting transcription. However, while interaction of yeast genes with nuclear pore proteins occurs at the nuclear periphery in association with the NPC, many genes in mammalian cells and Drosphila interact with soluble nuclear pore proteins in the nucleoplasm (Capelson et al., 2010; Liang et al., 2013; Light et al., 2013). Sub-diffusion for mammalian chromatin (which has been suggested to be less mobile than in yeast; Chubb et al., 2002) in a nucleus with a radius of $5 \mu \mathrm{m}$ would make it impossible (on a biologically meaningful timescale) for loci in the center of the nucleus to reach 
the periphery. In larger nuclei, recruitment of nuclear pore proteins to sites of action, regardless of their position, likely overcomes this obstacle.

Inter-chromosomal clustering is a widespread phenomenon in eukaryotes (Bantignies et al., 2011; Brickner et al., 2012; J. M. Brown et al., 2008; Cook and Marenduzzo, 2018; Eskiw et al., 2010; Gehlen et al., 2012; Haeusler et al., 2008; Noma et al., 2006; Ramos et al., 2006; Taddei et al., 2009; Thompson et al., 2003; Xu and Cook, 2008). Genes that are targeted to the NPC by shared transcription factors exhibit inter-chromosomal clustering (Brickner et al., 2012; Kim et al., 2019, 2017). Such clustering requires transcription factor(s) and nuclear pore proteins (Brickner et al., 2012; Chowdhary et al., 2017; Kim et al., 2019) but is also mechanistically distinguishable from targeting to the NPC (Brickner et al., 2016). Clustering persisted for 20-40s (Figure 6) and led to correlated movement between pairs of loci that were within 550nm (Figure 7). Importantly, independently correlating step size and step angle is sensitive to correlations among pairs of loci in a subset of the cells in the population. Such correlated movement, averaged over the entire population, would be more difficult to appreciate. This may explain why previous work tracking movement of pairs of active GAL1-10 alleles in yeast found little correlation in aggregate (Backlund et al., 2014).

Pairs of paths generated by either the simulation or the simulation + zip code do not lead to inter-chromosomal clustering, consistent with the observation that genes targeted to the NPC by different transcription factors do not exhibit clustering (Brickner et al., 2012). Therefore, while clustering requires transcription factors and interaction with the NPC, it represents a distinct physical interaction. Surprisingly, correlated movement was observed between loci separated by hundreds of nanometers, suggesting that it represents a large molecular complex, or more likely, an environment. Physical interactions that lead to phase-separation could encompasses groups of genes to create a (perhaps transient) nuclear sub-compartment (Hult et al., 2017). This is reminiscent of superenhancers, which exist within phase-separated droplets (Hnisz et al., 2017; Sabari et al., 2018) and are strongly associated with nuclear pore proteins 
(Ibarra et al., 2016). It is possible that phase separation is facilitated by multivalent interactions between natively unstructured nuclear pore proteins, which can form phase separated droplets in vitro (Frey et al., 2006; Frey and Gorlich, 2007). Such conditional phase separation would be regulated and specified by transcription factors, and potentially other transcriptional complexes such as Mediator or RNA polymerase II, to functionally compartmentalize the nucleus. 


\section{MATERIALS AND METHODS}

\section{Chemicals, reagents, and media}

All chemicals were purchased from Sigma-Aldrich unless otherwise noted. Media components were from Sunrise Science Products and $\alpha$-factor was from Zymo Research. Yeast and bacteria media and transformations were as described (Burke et al., 2000; Wood, 1983).

\section{Yeast Strains}

All yeast strains were derived from W303 (ade2-1 ura3-1 trp1-1 his3-11,15 leu2-3,112 can1-100) strains CRY1 (MATa) or CRY2 (MAT $\alpha$; Brickner and Fuller, 1997) and are listed in Supplementary Table S2. The $\mu$ NS cytoplasmic particle was expressed from plasmid

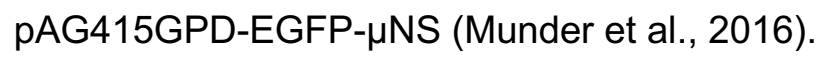

\section{Yeast culturing}

Yeast cultures were inoculated from a YPD agar plate into synthetic dextrose complete $(\mathrm{SDC})$ or drop out media and rotated at $30^{\circ} \mathrm{C}$ for $\geq 18 \mathrm{~h}$, diluting periodically to maintain the cultures at $\mathrm{OD}_{600}<0.8$. Before microscopy, cultures were diluted to $\leq 0.1 \mathrm{OD} / \mathrm{mL}$ and treated with $2 \mathrm{ng} / \mathrm{mL}$ of nocodazole for $2 \mathrm{~h}$. Cultures were then pelleted, washed, and resuspended in SDC to release from M-phase into G1-phase for 10 minutes. Cells were then pelleted again, concentrated, applied to a microscope slide, and covered with a glass coverslip for imaging.

For experiments involving mating pheromone, $100 \mu \mathrm{M} \alpha$-factor was added to the cultures following release from nocodazole arrest for at $\geq 30$ minutes. To release from pheromone arrest, cells were pelleted, washed into SDC and mounted for microscopy.

\section{Microscopy}

Confocal microscopy was performed in the Northwestern University Biological Imaging Facility. Tracking microscopy was performed on a Leica Spinning Disk Confocal Microscope (Leica DMI6000 inverted microscope equipped with Yokogawa CSU-X1 spinning disk and

Photometrics Evolve Delta512 camera), and static localization experiments (Figures 1B, 1D, 3, 
$5 \mathrm{C} \& 5 \mathrm{E})$ were performed on a Leica TCS SP8 Confocal Microscope.

For both single locus/particle MSD and multiple loci tracking, the same acquisition protocol was used. GFP-Lacl /LacO spots in G1-phase cells were imaged every 210ms for 200 frames in a single $z$-plane with a minimum of 40 biological replicates per experimental condition. Cells that did not remain immobilized or whose loci underwent no movement were excluded from our analysis. For peripheral targeting dynamics experiments (Figure 5F, G, \& I), LaclGFP/LacO128 arrays in G1-phase cells were imaged every 500ms for 600 frames and Pho88mCherry was imaged every 10 s to determine position with respect to the nuclear periphery (D'Urso et al., 2016; Egecioglu et al., 2014).

Static localization experiments (Figures 1B, 1D, 3, 5C \& 5E) were acquired as z-stacks encompassing the full yeast cell, and 30-50 cells were scored per biological replicate as described (Brickner et al., 2010; Brickner and Walter, 2004; Egecioglu et al., 2014). Each strain and condition included at least three biological replicates. To activate light-induced recruitment, cells imaged in Figure 4C were scanned with the 488nm laser every 10 seconds.

\section{Particle tracking and data analysis}

Tracking was performed using the ImageJ plugin MTrackJ. To accommodate clustering experiments (which typically have two or more fluorescent particles per nucleus), MTrackJ's region of tracking tool was utilized to ensure the signals from individual loci were tracked separately. Tracking data was output as a comma separated text file and analyzed with $\mathrm{R}$ scripts available via GitHub. (https://github.com/MCnu/R sim scripts). Repositioning analysis in Figure 4 utilized a lookup table that contained the frame and the position in which the signal from Lacl-GFP/LacO128 array of a given cell first colocalized with the Pho88-mCherry nuclear membrane signal. Tracking data for Figures 2, 3, 5, 6 and 7 and simulated paths for Figures 4, 5 and 7 are presented as Source data files associated with each Figure.

\section{Fractional Brownian motion simulations}

We model the dynamics of chromosomal loci in the cellular nucleus via a discrete-time 
random walk with continuously varying step size. This simulation is governed by Fractional Brownian Motion (FBM), which gives rise to anomalous diffusion of the locus. Anomalous diffusion is distinct from Brownian diffusion due to a nonlinear mean-squared displacement over time, with distinct behaviors for the super-diffusive $(\alpha>1)$ vs. sub-diffusive $(\alpha<1)$ regimes. Free fitting our MSD measurements for 23 different loci/conditions, we found an average $\alpha=$ 0.52 (not shown), matching that determined in previous work (Hajjoul et al., 2013). Therefore, for the simulations, we used $\alpha=0.52$. Following previous work (Lucas et al., 2014), we present Fractional Langevin dynamics simplified by the assumption of overdamping (i.e., no inertial term) and no driving force. In FBM, the statistical noise is a stationary Gaussian process with a mean equal to zero and a nonzero anticorrelation between successive steps (Meyer et al., 1999). This property is exploited to allow random vector generation with a given correlation structure (Dietrich and Newsam, 1997). We draw values for each simulated dimension of movement to generate the entire time series for a trajectory. We re-scale the vectors to an appropriate magnitude for given time units equal to $\tau$ using a $\Gamma$ parameter provided by nonlinear regression on experimental MSD data (where $\operatorname{MSD}(\tau)=\Gamma\left(\tau^{0.52}\right)$ ). No additional complications in our computational model are required to reproduce experimental MSD (Figure 4 - Supplement 1 A \& B).

To properly simulate chromatin diffusion within the confines of the nucleus, we added an impassable boundary to serve as a nuclear membrane. Recent work on the behavior of FBM and the Fractional Langevin Equation in finite volumes of space showed that the presence of boundaries and the handling of those boundary conditions can affect the long-time scale distribution close to the edges of the domain (Guggenberger et al., 2019; Vojta et al., 2020, 2019; Wada and Vojta, 2018). These studies agree with our findings that in the sub-diffusive regime, 'depletion' occurs at the boundary (Figure 4, Supplement $1 C \& D)$. This depletion at the periphery is rationalized by the fact that because successive steps are anticorrelated, a step 
which would take the particle over the boundary is likely to be followed by one which would take it away from it. Such depletion is not observed in experimental distributions of control and noncontrol specimens. It is possible that the physicochemical landscape of the periphery or the region near the periphery involve many interactions which have the effect of attracting the chromatin locus to the periphery, but such effects are not present in the aforementioned studies (which do not consider transient binding interactions with a hard wall). Because our particle is actually a segment of a much larger polymer, we instead decided to regenerate the underlying noise time series whenever the trajectory collides with the periphery to negate the effects of prior movement. This adaptation succeeded in creating a uniform distribution of positions across the nucleus. However, we acknowledge that our theoretical particle no longer satisfies the fluctuation dissipation theorem inherent to all Brownian motion, including FBM. More careful investigation of the behavior of chromatin at the boundary in silica and in vivo will help clarify the validity of this modification.

Binding of chromatin to NPCs was modeled using a simple two-state Markov model wherein a locus within the peripheral region (an annulus extending 50 nanometers from the nuclear boundary), can assume a bound state in the next step with a defined probability. Particles bound to the NPC remain bound at a second defined probability for every step until it becomes unbound. A particle bound to the NPC is assumed to be interacting strongly with an NPC, their motion is inhibited, but not entirely arrested. We therefore scaled the step sizes of particles in the bound state with $\Gamma$ and $\alpha$ parameters derived from non-linear regression of the MSD for the spindle pole body (Figure 2). In this way, we simulate the effective "pausing" of chromatin motion due to NPC interaction.

\section{Source Code}

Our simulation data and source code are openly available. Our simulations were implemented in Python, with routine algorithms like random noise generation or the fast Fourier transform from the NumPy library (Harris et al., 2020) and all other code implemented using 
bioRxiv preprint doi: https://doi.org/10.1101/2021.01.16.426968; this version posted January 17, 2021. The copyright holder for this preprint

(which was not certified by peer review) is the author/funder, who has granted bioRxiv a license to display the preprint in perpetuity. It is made available under aCC-BY 4.0 International license.

custom libraries is available on GitHub (https://github.com/MCnu/YGRW). Analytical pipeline of two-dimensional tracking data is also available. All analyses were implemented in $\mathrm{R}$ and scripts are available on GitHub (https://github.com/MCnu/R sim scripts). 


\section{Acknowledgments}

The authors would like to thank Dr. Rebecca Menssen and Dr. Madhav Mani for guidance on dynamics analysis; Dr. Reza Vafabakhsh, Dr. Laura Lackner, Dr. Alec Wang, Dr. John Marko, as well as current and former members of the Brickner laboratory for helpful discussions and comments on the manuscript; the Lackner Lab for sharing plasmids, reagents, and guidance with microscopy; the BIF core facility staff at Northwestern University; Dr. Thomas Vojta for discussions on FBM; and Dr. Yaojun Zhang and Dr. Olga Dudko for access to their MATLAB code used in Lucas et al., 2014. MCS was supported by the Cellular and Molecular Basis of Disease NIH T32 GM008061 and SBT received support from the U.S. Department of Energy through the Computational Science Graduate Fellowship under grant number DE-FG0297ER25308. This work was funded by NIH grants R01 GM118712 and R35 GM136419 and National Cancer Institute U54 CA193419 (JHB). 


\section{FIGURE LEGENDS}

Figure 1. Continuous and dynamic targeting to the NPC. (A) Representative confocal micrographs of cells having the LacO array integrated at a locus of interest, expressing GFPLacl and Pho88-mCherry (Robinett et al., 1996; Brickner \& Walter, 2004; Brickner et al., 2019) and scored as either nucleoplasmic (left) or peripheral (right). (B) Peripheral localization (\% of cells \pm SEM) of URA3 and HIS4 in cells grown \pm histidine. The hatched blue line, here and throughout: peripheral localization predicted by chance. (C, E-G) Kymographs of ten cells with a LacO array integrated at HIS4 (C), URA3 (E), INO1 (F) or URA3:GRS1 (G) were grown in the indicated medium and scored for peripheral localization every $10 \mathrm{~s}$ for $5 \mathrm{~min}$. Yellow: peripheral; Purple: nucleoplasmic. (D) Peripheral localization ( \pm SEM) of URA3, INO1, URA3:INO1, and URA3:GRS1 in cells grown \pm inositol. (H-J) Summary plots from panels $\mathrm{C}, \mathrm{E}-\mathrm{G}:(\mathrm{H})$ mean percentage of cells $( \pm S D)$ in which the locus is peripheral at each time point (i.e., each dot represents a summary of a single column from kymographs); (I) mean percentage of time ( \pm SD) each locus spent colocalized with the nuclear envelope (i.e., each dot represents a summary of a single row from kymographs); and $(\mathrm{J})$ the distribution and median duration of periods of peripheral localization of each locus.

Figure 2. Mean squared displacement of chromatin sub-diffusion. (A) Schematic of fluorescent foci within the yeast cell. Fluorescently tagged spindle pole body (SPB), cytoplasmic $\mu$ NS, and chromosomal locus were tracked over $200 \times 200 m s$. Example micrographs of each particle (left) and overlaid path (right) are shown for each. Scale bar $=1 \mu \mathrm{m}$. (B) Average mean squared displacement (MSD) for $\mu$ NS (orange), SPB (purple), 10 nucleoplasmic loci (grey; listed in Table S1) and two telomeres (red) at different time intervals $(\tau)$. The ribbon around the mean represents standard error. (C) Mean MSD \pm standard deviation for $\tau=200 \mathrm{~ms}$ for each chromosomal locus in (B) vs. $\log _{10}$ (base pairs) to the nearest tether point (centromere or 
telomere). (D-F) MSD plots of INO1 (D) URA3 (E) or HIS4 (F) in cells grown in the indicated media. In all plots, the dashed line represents the MSD of the SPB. ${ }^{*} p<0.05$ based on Kolmogorov-Smirnov test comparing MSDs at the indicated times.

Figure 2 - Source data 1. Comma separated tables of tracking data used for Figure 2B, D, E \& F.

Figure 3. Interaction with the NPC reduces chromatin sub-diffusion. (A-F) MSD of URA3 (A-D) and INO1 (E \& F) in strains grown in the indicated media. Dark line indicates average MSD, ribbon = bootstrapped SEM. Insets: peripheral localization of each locus (mean \% of cells \pm SEM). The GRS1 zip code from the INO1 promoter (A \& C) or the Gcn4 binding site (B \& D) were integrated and integrated at URA3 in wild type (A \& B) or nup2 $\triangle(C \& D)$ strains. MSD of INO1 in ino2 $\Delta(\mathrm{E})$ or opi1s $(\mathrm{F})$ strains. ${ }^{*} p<0.05$ based on Kolmogorov-Smirnov test comparing MSD at the indicated time points.

Figure 3 - Source data 1. Comma separated tables of tracking data used for Figure 3.

Figure 4. A fractional Brownian motion simulation of chromatin sub-diffusion. (A \& $C$ ) Randomly selected example paths over 5 minutes at $200 \mathrm{~ms}$ time resolution. Color scale represents time. Paths were simulated using parameters (diffusion coefficient and anomalous exponent) extracted from a non-linear regression fit to URA3 MSD (A; simulation) or by also allowing interaction at the nuclear envelope, slowing sub-diffusion to that of the SPB (C; simulation + zip code). (B \& D) 150,000 positions visited in 100 simulated 5-minute paths at 200ms time resolution for the simulation (B) or the simulation +zip code (D). (E) Peripheral localization (i.e., positioned $\leq 150 \mathrm{~nm}$ from the edge of the nucleus) every 10 s over 10 minutes for 100 paths from the simulation (top) and simulation + zip code (bottom). (F) Summary plots for percent of cells in that scored as peripheral at each time (left) or the percent of time each cell scored as peripheral (right) in either the simulation or the simulation + zip code. (G) MSD of the 
paths from the simulation or the simulation + zip code. Dark line is the mean and the colored band represents the bootstrapped standard error.

\section{Figure 4 - Figure Supplement 1. Comparison of simulations of sub-diffusion of}

nucleoplasmic chromatin. Four different simulations of chromatin diffusion were compared with URA3 for MSD (A \& B) or nuclear position $(C \& D)$. The uniform simulation generated uniformly distributed step sizes in the $x$ and $y$ dimensions with a mean step size of $0 \pm 0.05 \mu m$. The Gaussian simulation generated normally distributed step-sizes sizes in the $\mathrm{x}$ and $\mathrm{y}$ dimensions with a mean step size of 0 and a sigma of $0.025 \mu \mathrm{m}$. The fractional Brownian motion simulation (FBM) and a modified FBM with regeneration are detailed in Materials and Methods $\left(\Gamma=0.015 \mu \mathrm{m}^{2} \mathrm{~s}^{-1}, \alpha=0.52\right)$. Each simulation condition consists of one hundred trajectories, each composed of 2000 steps at $210 \mathrm{~ms}$ step time intervals. (A) Plot of MSD for URA3 and the different simulations. (B) $X$-squared sum of differences between mean MSD plots of URA3 and each simulation ( $t \leq 4 \mathrm{~s})$. (C) Positions generated over 5 minutes of 100 simulations for each type. (D) Histograms of radial positions.

\section{Figure 4 - Figure Supplement 2. Optimization of binding probability and retention}

probability by comparison with URA3:GRS1. The probability of binding and the probability of retention was independently varied and compared with the behavior of URA3:GRS1. (A \& B) $X$ squared differences between mean MSD plots of URA3:GRS1 and each simulation ( $\tau \leq 4 \mathrm{~s})$.

Each panel represents a set of simulated paths with the indicated probability of remaining bound $(A)$ or the probability of binding $(B)$. Within each panel, the probability of binding $(A)$ or remaining bound $(B)$ was varied. The hatched line is the $C$-squared difference between the simulation with both binding and retention probabilities equal to zero and MSD of URA3:GRS1, for comparison. (C \& D) Percent of time per cell (C) and the percent of cells at each time (D), that loci occupied the periphery (outer $150 \mathrm{~nm}$ shell of $1 \mu \mathrm{m}$ radius nucleus) for URA3, 
URA3:GRS1 (experimental observations from Figure 1) and each combination of binding and retention probabilities. (E) Kymographs as in Figure 1 (experimental data from Figure 1 shown in inset), for each simulated combination of binding and retention probabilities. For all panels, red boxes highlight simulations similar to URA3:GRS1 for the analyzed component.

Figure 4 - Source data 1. Comma separated tables of simulated paths used for Figure 4.

Figure 5. Repositioning from the nucleoplasm to the NPC. (A). Simulated repositioning. Simulated paths, using either the fractional Brownian simulation or the simulation + zip code, were initiated at random positions within $2 \mu \mathrm{m}$ diameter nucleus and followed for 20 minutes ( $200 \mathrm{~ms}$ resolution). Colocalization with the periphery (i.e., $\leq 150 \mathrm{~nm}$ from the edge) was scored for each simulation at each time and smoothed by averaging over 10 s windows. For each time point, three replicates of 33 paths were scored to generate an average (points) \pm SEM (error bars). Blue, hatched line: peripheral localization expected for a random distribution. (B) Schematic for repositioning to the nuclear periphery upon release from a-factor arrest. (C) Peripheral localization (\% of cells \pm SEM) of URA3 or URA3:GRS1 over time after removing afactor. (D) Schematic for optogenetic light-induced targeting to the nuclear periphery. (E) Peripheral of URA3:LexABS in strains expressing either LexA-GCN4, LexA-CRY2 + mutant $\mathrm{PD}_{\mathrm{GCN} 4}-\mathrm{CIB} 1$ or LexA-CRY2 + wild type $\mathrm{PD}_{\mathrm{GCN} 4}$ at the indicated times after illumination with $488 \mathrm{~nm}$ light. (F-I) Summary plots of velocity $(F)$, arrival time $(G)$, and angular deviation from an ideal path (I) from each cell before initial colocalization with nuclear periphery. White circles are the mean values and error bars represent the standard deviation. For panels F-I, simulated paths were initiated at random positions within a $1 \mu \mathrm{m}$ diameter sphere in the center of the $2 \mu \mathrm{m}$ diameter nucleus and followed for 5 minutes. Paths that did not make contact with the nuclear periphery were excluded.

Figure 5 - Source data 1. Comma separated tables of simulated paths and tracking data used for Figure 5. 
Figure 6. Dynamics of inter-chromosomal clustering. (A) Confocal micrographs of diploid cells with two loci marked with LacO arrays, expressing Lacl-GFP and Pho88-mCherry.

Distance between LacO arrays was measured over 200 x 200ms time points in 40-50 cells (BD). (B) Distribution of mean distances between loci for each cell, with the median for each strain or condition indicated with a white dash. P-values $<0.05$ from the Kolmogorov-Smirnov test are shown. (C) Distribution of lifetimes during which $d \leq 0.55 \mu \mathrm{m}$. Dot $=$ mean, error bars $=\mathrm{SD}$. (D) The fraction of all time points that $d \leq 0.55 \mu \mathrm{m}$ for each strain and media condition. For panels BD, mean distances, lifetimes and fraction of timepoints clustered were also determined for pairs of randomly selected simulated paths (with or without zip code; red).

Figure 6 - Source data 1. Comma separated tables of simulated paths and tracking data used for Figure 6.

Figure 7. Inter-chromosomal clustering leads to coordinated movement. (A) Workflow for tracking and analyzing movement of LacO array pairs. For each step from a time series, step distance and step angle are measured (top) and the difference in angles computed (bottom). (B) Each time series produces two values: a Pearson correlation coefficient (cor(d)) for all step sizes and a mean difference in angles $(\Delta \theta)$. (C) Each cell produces a single point on the summary plot (orange). Grey lines highlight $\operatorname{cor}(\mathrm{d})=0$ and $\Delta \theta=\pi / 2$. Uncorrelated movement of two loci would be expected to cluster near $\operatorname{cor}(d)=0$ and $\Delta \theta=\pi / 2$, while perfectly correlated movement would result in $\operatorname{cor}(d)=1$ and $\Delta \theta=0$. (D-L) Summary plots for correlation analysis of the indicated pairs of loci in the indicated strains grown in the media described in the headers. Cells in which the mean distance between the loci was $>0.55 \mu \mathrm{m}$ appear in orange, while cells in which the mean distance between the loci was $\leq 0.55 \mu \mathrm{m}$ appear in purple. For each plot, the slope and $R^{2}$ for a linear relationship between $\operatorname{cor}(\mathrm{d})$ and $\Delta \theta$ are indicated. $40-50$ cells were analyzed per strain and condition. Simulations are the 50 pairs of paths generated for Figure 6 .

Figure 7 - Figure Supplement 1. Dynamic coordination analysis of URA3. Diploid strains 
bioRxiv preprint doi: https://doi.org/10.1101/2021.01.16.426968; this version posted January 17, 2021. The copyright holder for this preprint

(which was not certified by peer review) is the author/funder, who has granted bioRxiv a license to display the preprint in perpetuity. It is made available under aCC-BY 4.0 International license.

having the LacO array integrated at both alleles of URA3 were grown in SDC \pm histidine, the loci were tracked and analyzed for correlated step size and step angle as described for Figure 7.

The slope and $R^{2}$ for each plot is for a linear relationship between $\operatorname{cor}(\mathrm{d})$ and $\Delta \theta$.

Figure 7 - Source data 1. Comma separated tables of simulated paths and tracking data used for Figure 7. 


\section{REFERENCES}

Ahmed S, Brickner DG, Light WH, Cajigas I, McDonough M, Froyshteter AB, Volpe T, Brickner JH. 2010. DNA zip codes control an ancient mechanism for gene targeting to the nuclear periphery. Nat Cell Biol 12:111. doi:10.1038/ncb2011

Apostolou E, Thanos D. 2008. Virus Infection Induces NF-kappaB-dependent interchromosomal associations mediating monoallelic IFN-beta gene expression. Cell 134:85-96. doi:10.1016/j.cell.2008.05.052

Backlund MP, Joyner R, Weis K, Moerner WE. 2014. Correlations of three-dimensional motion of chromosomal loci in yeast revealed by the double-helix point spread function microscope. Mol Biol Cell 25:3619-29.

Bantignies F, Roure V, Comet I, Leblanc B, Schuettengruber B, Bonnet J, Tixier V, Mas A, Cavalli G. 2011. Polycomb-dependent regulatory contacts between distant Hox loci in Drosophila. Cell 144:214-26. doi:10.1016/j.cell.2010.12.026

Benedetti L, Barentine AES, Messa M, Wheeler H, Bewersdorf J, Camilli PD. 2018. Lightactivated protein interaction with high spatial subcellular confinement. Proc National Acad Sci 115:201713845. doi:10.1073/pnas.1713845115

Brickner D, Coukos R, Brickner J. 2015. INO1 transcriptional memory leads to DNA zip codedependent interchromosomal clustering. Microb Cell 2:481-490. doi:10.15698/mic2015.12.242

Brickner DG, Ahmed S, Meldi L, Thompson A, Light W, Young M, Hickman TL, Chu F, Fabre E, Brickner JH. 2012. Transcription Factor Binding to a DNA Zip Code Controls Interchromosomal Clustering at the Nuclear Periphery. Dev Cell 22:1234-1246. doi:10.1016/j.devcel.2012.03.012

Brickner DG, Brickner JH. 2010. Cdk Phosphorylation of a Nucleoporin Controls Localization of Active Genes through the Cell Cycle. Mol Biol Cell 21:3421-3432. doi:10.1091/mbc.e10-010065

Brickner DG, Cajigas I, Fondufe-Mittendorf Y, Ahmed S, Lee P-C, Widom J, Brickner JH. 2007. H2A.Z-Mediated Localization of Genes at the Nuclear Periphery Confers Epigenetic Memory of Previous Transcriptional State. Plos Biol 5:e81. doi:10.1371/journal.pbio.0050081

Brickner DG, Light W, Brickner JH. 2010. Chapter 22 Quantitative Localization of Chromosomal Loci by Immunofluorescence. Methods Enzymol 470:569-580. doi:10.1016/s0076$6879(10) 70022-7$

Brickner DG, Randise-Hinchliff C, Corbin ML, Liang JM, Kim S, Sump B, D'Urso A, Kim SH, Satomura A, Schmit H, Coukos R, Hwang S, Watson R, Brickner JH. 2019. The Role of Transcription Factors and Nuclear Pore Proteins in Controlling the Spatial Organization of the Yeast Genome. Dev Cell 49:936-947.e4. doi:10.1016/j.devcel.2019.05.023 
Brickner DG, Sood V, Tutucci E, Coukos R, Viets K, Singer RH, Brickner JH. 2016. Subnuclear positioning and interchromosomal clustering of the GAL1-10 locus are controlled by separable, interdependent mechanisms. Mol Biol Cell 27:2980-2993. doi:10.1091/mbc.e1603-0174

Brickner J. 2017. Genetic and epigenetic control of the spatial organization of the genome. Mol Biol Cell 28:364-369. doi:10.1091/mbc.e16-03-0149

Brickner JH, Fuller RS. 1997. SOI1 encodes a novel, conserved protein that promotes TGNendosomal cycling of Kex $2 p$ and other membrane proteins by modulating the function of two TGN localization signals. J Cell Biol 139:23-36.

Brickner JH, Walter P. 2004. Gene Recruitment of the Activated INO1 Locus to the Nuclear Membrane. Plos Biol 2:e342. doi:10.1371/journal.pbio.0020342

Brown CR, Kennedy CJ, Delmar VA, Forbes DJ, Silver PA. 2008. Global histone acetylation induces functional genomic reorganization at mammalian nuclear pore complexes. Gene Dev 22:627-639. doi:10.1101/gad.1632708

Brown JM, Green J, Neves RP das, Wallace HA, Smith AJ, Hughes J, Gray N, Taylor S, Wood WG, Higgs DR, Iborra FJ, Buckle VJ. 2008. Association between active genes occurs at nuclear speckles and is modulated by chromatin environment. $J$ Cell Biology 182:1083-97. doi:10.1083/jcb.200803174

Brown JM, Leach J, Reittie JE, Atzberger A, Lee-Prudhoe J, Wood WG, Higgs DR, Iborra FJ, Buckle VJ. 2006. Coregulated human globin genes are frequently in spatial proximity when active. J Cell Biology 172:177-87. doi:10.1083/jcb.200507073

Burke D, Dawson D, Stearns T. 2000. Methods in Yeast Genetics.

Bystricky K, Heun P, Gehlen L, Langowski J, Gasser SM. 2004. Long-range compaction and flexibility of interphase chromatin in budding yeast analyzed by high-resolution imaging techniques. Proc Natl Acad Sci U S A 101:16495-500.

Cabal GG, Genovesio A, Rodriguez-Navarro S, Zimmer C, Gadal O, Lesne A, Buc H, Feuerbach-Fournier F, Olivo-Marin JC, Hurt EC, Nehrbass U. 2006. SAGA interacting factors confine sub-diffusion of transcribed genes to the nuclear envelope. Nature 441:770-3.

Capelson M, Liang Y, Schulte R, Mair W, Wagner U, Hetzer MW. 2010. Chromatin-bound nuclear pore components regulate gene expression in higher eukaryotes. Cell 140:372-83. doi:10.1016/j.cell.2009.12.054

Casolari JM, Brown CR, Drubin DA, R, o OJ, Silver PA. 2005. Developmentally induced changes in transcriptional program alter spatial organization across chromosomes. Genes Dev 19:1188-98.

Casolari JM, Brown CR, Komili S, West J, Hieronymus H, Silver PA. 2004. Genome-wide localization of the nuclear transport machinery couples transcriptional status and nuclear organization. Cell 117:427-39. 
Chowdhary S, Kainth AS, Gross DS. 2017. Heat Shock Protein Genes Undergo Dynamic Alteration in Their Three-Dimensional Structure and Genome Organization in Response to Thermal Stress. Mol Cell Biol 37:e00292-17. doi:10.1128/mcb.00292-17

Chubb JR, Boyle S, Perry P, Bickmore WA. 2002. Chromatin motion is constrained by association with nuclear compartments in human cells. Curr Biol 12:439-45.

Cook PR, Marenduzzo D. 2018. Transcription-driven genome organization: a model for chromosome structure and the regulation of gene expression tested through simulations. Nucleic Acids Res 46:gky763. doi:10.1093/nar/gky763

Dai Y, Li C, Pei G, Dong X, Ding G, Zhao Z, Li Y, Jia P. 2018. Multiple transcription factors contribute to inter-chromosomal interaction in yeast. Bmc Syst Biol 12:140. doi:10.1186/s12918-018-0643-1

Dieppois G, Iglesias N, Stutz F. 2006. Cotranscriptional recruitment to the mRNA export receptor Mex67p contributes to nuclear pore anchoring of activated genes. Mol Cell Biol 26:7858-70.

Dietrich CR, Newsam GN. 1997. Fast and Exact Simulation of Stationary Gaussian Processes through Circulant Embedding of the Covariance Matrix. Siam J Sci Comput 18:1088-1107. doi:10.1137/s1064827592240555

Dilworth DJ, Tackett AJ, Rogers RS, Yi EC, Christmas RH, Smith JJ, Siegel AF, Chait BT, Wozniak RW, Aitchison JD. 2005. The mobile nucleoporin Nup2p and chromatin-bound Prp20p function in endogenous NPC-mediated transcriptional control. J Cell Biology 171:955-65. doi:10.1083/jcb.200509061

D'Urso A, Takahashi Y, Xiong B, Marone J, Coukos R, Randise-Hinchliff C, Wang J-P, Shilatifard A, Brickner JH. 2016. Set1/COMPASS and Mediator are repurposed to promote epigenetic transcriptional memory. Elife 5:e16691. doi:10.7554/elife.16691

Egecioglu DE, D'Urso A, Brickner DG, Light WH, Brickner JH. 2014. Chapter 21 Approaches to Studying Subnuclear Organization and Gene-Nuclear Pore Interactions. Methods Cell Biol 122:463-485. doi:10.1016/b978-0-12-417160-2.00021-7

Eskiw CH, Cope NF, Clay I, Schoenfelder S, Nagano T, Fraser P. 2010. Transcription factories and nuclear organization of the genome. Cold Spring Harb Sym 75:501-6. doi:10.1101/sqb.2010.75.046

Femino AM, Fay FS, Fogarty K, Singer RH. 1998. Visualization of Single RNA Transcripts in Situ. Science 280:585-590. doi:10.1126/science.280.5363.585

Frey S, Gorlich D. 2007. A saturated FG-repeat hydrogel can reproduce the permeability properties of nuclear pore complexes. Cell 130:512-23. doi:10.1016/j.cell.2007.06.024

Frey S, Richter RP, Gorlich D. 2006. FG-rich repeats of nuclear pore proteins form a threedimensional meshwork with hydrogel-like properties. Science 314:815-7.

doi:10.1126/science.1132516 
Gasser SM. 2002. Visualizing chromatin dynamics in interphase nuclei. Science 296:1412-6.

Gehlen LR, Gruenert G, Jones MB, Rodley CD, Langowski J, O’Sullivan JM. 2012.

Chromosome positioning and the clustering of functionally related loci in yeast is driven by chromosomal interactions. Nucleus 3:370-83. doi:10.4161/nucl.20971

Greenberg ML, Goldwasser P, Henry SA. 1982a. Characterization of a yeast regulatory mutant constitutive for synthesis of inositol-1-phosphate synthase. Mol Gen Genet 186:157-63.

Greenberg ML, Reiner B, Henry SA. 1982b. Regulatory mutations of inositol biosynthesis in yeast: isolation of inositol-excreting mutants. Genetics 100:19-33.

Guet D, Burns LT, Maji S, Boulanger J, Hersen P, Wente SR, Salamero J, Dargemont C. 2015. Combining Spinach-tagged RNA and gene localization to image gene expression in live yeast. Nat Commun 6:8882. doi:10.1038/ncomms9882

Guggenberger T, Pagnini G, Vojta T, Metzler R. 2019. Fractional Brownian motion in a finite interval: correlations effect depletion or accretion zones of particles near boundaries. New J Phys 21:022002. doi:10.1088/1367-2630/ab075f

Haeusler RA, Pratt-Hyatt M, Good PD, Gipson TA, Engelke DR. 2008. Clustering of yeast tRNA genes is mediated by specific association of condensin with tRNA gene transcription complexes. Gene Dev 22:2204-14. doi:10.1101/gad.1675908

Hajjoul H, Mathon J, Ranchon H, Goiffon I, Mozziconacci J, Albert B, Carrivain P, Victor J-M, Gadal O, Bystricky K, Bancaud A. 2013. High-throughput chromatin motion tracking in living yeast reveals the flexibility of the fiber throughout the genome. Genome Res 23:1829-1838. doi:10.1101/gr.157008.113

Harris CR, Millman KJ, Walt SJ van der, Gommers R, Virtanen P, Cournapeau D, Wieser E, Taylor J, Berg S, Smith NJ, Kern R, Picus M, Hoyer S, Kerkwijk MH van, Brett M, Haldane A, Río JF del, Wiebe M, Peterson P, Gérard-Marchant P, Sheppard K, Reddy T, Weckesser W, Abbasi H, Gohlke C, Oliphant TE. 2020. Array programming with NumPy. Nature 585:357362. doi:10.1038/s41586-020-2649-2

Hediger F, Berthiau AS, Houwe G van, Gilson E, Gasser SM. 2006. Subtelomeric factors antagonize telomere anchoring and Tel1-independent telomere length regulation. Embo $\mathrm{J}$ 25:857-67.

Hediger F, Gasser SM. 2002. Nuclear organization and silencing: putting things in their place. Nat Cell Biol 4:E53-5.

Hediger F, Neumann FR, Houwe GV, Dubrana K, Gasser SM. 2002. Live imaging of telomeres: yKu and Sir proteins define redundant telomere-anchoring pathways in yeast. Curr Biol 12:2076-89.

Heun P, Laroche T, Shimada K, Furrer P, Gasser SM. 2001. Chromosome dynamics in the yeast interphase nucleus. Science 294:2181-6. 
Heyken WT, Repenning A, Kumme J, Schuller HJ. 2005. Constitutive expression of yeast phospholipid biosynthetic genes by variants of Ino2 activator defective for interaction with Opi1 repressor. Mol Microbiol 56:696-707.

Hnisz D, Shrinivas K, Young RA, Chakraborty AK, Sharp PA. 2017. A Phase Separation Model for Transcriptional Control. Cell 169:13-23. doi:10.1016/j.cell.2017.02.007

Homouz D, Kudlicki AS. 2013. The 3D Organization of the Yeast Genome Correlates with CoExpression and Reflects Functional Relations between Genes. Plos One 8:e54699. doi:10.1371/journal.pone.0054699

Hult C, Adalsteinsson D, Vasquez PA, Lawrimore J, Bennett M, York A, Cook D, Yeh E, Forest MG, Bloom K. 2017. Enrichment of dynamic chromosomal crosslinks drive phase separation of the nucleolus. Nucleic Acids Res 45:gkx741-. doi:10.1093/nar/gkx741

Ibarra A, Benner C, Tyagi S, Cool J, Hetzer MW. 2016. Nucleoporin-mediated regulation of cell identity genes. Gene Dev 30:2253-2258. doi:10.1101/gad.287417.116

Jacinto FV, Benner C, Hetzer MW. 2015. The nucleoporin Nup153 regulates embryonic stem cell pluripotency through gene silencing. Gene Dev 29:1224-38. doi:10.1101/gad.260919.115

Jin QW, Fuchs J, Loidl J. 2000. Centromere clustering is a major determinant of yeast interphase nuclear organization. J Cell Sci 113 ( Pt 11):1903-12.

Kapoor P, Chen M, Winkler DD, Luger K, Shen X. 2013. Evidence for monomeric actin function in INO80 chromatin remodeling. Nat Struct Mol Biol 20:426-432. doi:10.1038/nsmb.2529

Kim S, Dunham MJ, Shendure J. 2019. A combination of transcription factors mediates inducible interchromosomal contacts. Elife 8:e42499. doi:10.7554/elife.42499

Kim S, Liachko I, Brickner DG, Cook K, Noble WS, Brickner JH, Shendure J, Dunham MJ. 2017. The dynamic three-dimensional organization of the diploid yeast genome. Elife 6:e23623. doi:10.7554/elife. 23623

Lapetina DL, Ptak C, Roesner UK, Wozniak RW. 2017. Yeast silencing factor Sir4 and a subset of nucleoporins form a complex distinct from nuclear pore complexes. J Cell Biol 216:31453159. doi:10.1083/jcb.201609049

Liang Y, Franks TM, Marchetto MC, Gage FH, Hetzer MW. 2013. Dynamic association of NUP98 with the human genome. PLoS Genet 9:e1003308.

Light WH, Brickner DG, Brand VR, Brickner JH. 2010. Interaction of a DNA Zip Code with the Nuclear Pore Complex Promotes H2A.Z Incorporation and INO1 Transcriptional Memory. Mol Cell 40:112-125. doi:10.1016/j.molcel.2010.09.007

Light WH, Freaney J, Sood V, Thompson A, D'Urso A, Horvath CM, Brickner JH. 2013. A Conserved Role for Human Nup98 in Altering Chromatin Structure and Promoting Epigenetic Transcriptional Memory. Plos Biol 11:e1001524. doi:10.1371/journal.pbio.1001524 
Lin C, Yang L, Tanasa B, Hutt K, Ju BG, Ohgi K, Zhang J, Rose DW, Fu XD, Glass CK, Rosenfeld MG. 2009. Nuclear receptor-induced chromosomal proximity and DNA breaks underlie specific translocations in cancer. Cell 139:1069-83.

Lucas JS, Zhang Y, Dudko OK, Murre C. 2014. 3D Trajectories Adopted by Coding and Regulatory DNA Elements: First-Passage Times for Genomic Interactions. Cell 158:339_ 352. doi:10.1016/j.cell.2014.05.036

Luthra R, Kerr SC, Harreman MT, Apponi LH, Fasken MB, Ramineni S, Chaurasia S, Valentini SR, Corbett AH. 2007. Actively transcribed GAL genes can be physically linked to the nuclear pore by the SAGA chromatin modifying complex. J Biol Chem 282:3042-9.

Mandelbrot BB, Ness JWV. 1968. Fractional Brownian Motions, Fractional Noises and Applications. Siam Rev 10:422-437. doi:10.1137/1010093

Marshall W.F, Straight A, Marko JF, Swedlow J, Dernburg A, Belmont A, Murray AW, Agard DA, Sedat JW. 1997. Interphase chromosomes undergo constrained diffusional motion in living cells. Curr Biol 7:930-939. doi:10.1016/s0960-9822(06)00412-x

Marshall W. F. , Straight A, Marko JF, Swedlow J, Dernburg A, Belmont A, Murray AW, Agard DA, Sedat JW. 1997. Interphase chromosomes undergo constrained diffusional motion in living cells. Curr Biol 7:930-9.

Meyer Y, Sellan F, Taqqu MS. 1999. Wavelets, generalized white noise and fractional integration: The synthesis of fractional Brownian motion. J Fourier Anal Appl 5:465-494. doi:10.1007/bf01261639

Miné-Hattab J, Rothstein R. 2013. DNA in motion during double-strand break repair. Trends Cell Biol 23:529-536. doi:10.1016/j.tcb.2013.05.006

Mirkin EV, Chang FS, Kleckner N. 2013. Dynamic Trans Interactions in Yeast Chromosomes. Plos One 8:e75895. doi:10.1371/journal.pone.0075895

Misteli T. 2020. The Self-Organizing Genome: Principles of Genome Architecture and Function. Cell 183:28-45. doi:10.1016/j.cell.2020.09.014

Mueller PP, Harashima S, Hinnebusch AG. 1987. A segment of GCN4 mRNA containing the upstream AUG codons confers translational control upon a heterologous yeast transcript. Proc Natl Acad Sci U S A 84:2863-7.

Mueller PP, Hinnebusch AG. 1986. Multiple upstream AUG codons mediate translational control of GCN4. Cell 45:201-207. doi:10.1016/0092-8674(86)90384-3

Munder MC, Midtvedt D, Franzmann T, Nüske E, Otto O, Herbig M, Ulbricht E, Müller P, Taubenberger A, Maharana S, Malinovska L, Richter D, Guck J, Zaburdaev V, Alberti S. 2016. A pH-driven transition of the cytoplasm from a fluid- to a solid-like state promotes entry into dormancy. Elife 5:e09347. doi:10.7554/elife.09347 
Noma K, Cam HP, Maraia RJ, Grewal SI. 2006. A role for TFIIIC transcription factor complex in genome organization. Cell 125:859-72. doi:10.1016/j.cell.2006.04.028

Pascual-Garcia P, Debo B, Aleman JR, Talamas JA, Lan Y, Nguyen NH, Won KJ, Capelson M. 2017. Metazoan Nuclear Pores Provide a Scaffold for Poised Genes and Mediate Induced Enhancer-Promoter Contacts. Mol Cell 66:63-76 e6. doi:10.1016/j.molcel.2017.02.020

Pascual-Garcia P, Jeong J, Capelson M. 2014. Nucleoporin Nup98 associates with Trx/MLL and NSL histone-modifying complexes and regulates Hox gene expression. Cell Reports 9:433-42. doi:10.1016/j.celrep.2014.09.002

Ramos E, Ghosh D, Baxter E, Corces VG. 2006. Genomic organization of gypsy chromatin insulators in Drosophila melanogaster. Genetics 172:2337-49.

doi:10.1534/genetics.105.054742

Randise-Hinchliff C, Coukos R, Sood V, Sumner MC, Zdraljevic S, Sholl LM, Brickner DG, Ahmed S, Watchmaker L, Brickner JH. 2016. Strategies to regulate transcription factormediated gene positioning and interchromosomal clustering at the nuclear periphery. $J$ Cell Biology 212:633-646. doi:10.1083/jcb.201508068

Robinett CC, Straight A, Li G, Willhelm C, Sudlow G, Murray A, Belmont AS. 1996. In vivo localization of DNA sequences and visualization of large-scale chromatin organization using lac operator/repressor recognition. J Cell Biol 135:1685-700.

Rodriguez J, Larson DR. 2020. Transcription in Living Cells: Molecular Mechanisms of Bursting. Annu Rev Biochem 89:1-24. doi:10.1146/annurev-biochem-011520-105250

Rohner S, Kalck V, Wang X, Ikegami K, Lieb JD, Gasser SM, Meister P. 2013. Promoter- and RNA polymerase II-dependent hsp-16 gene association with nuclear pores in Caenorhabditis elegans. J Cell Biol 200:589-604.

Sabari BR, Dall'Agnese A, Boija A, Klein IA, Coffey EL, Shrinivas K, Abraham BJ, Hannett NM, Zamudio AV, Manteiga JC, Li CH, Guo YE, Day DS, Schuijers J, Vasile E, Malik S, Hnisz D, Lee TI, Cisse II, Roeder RG, Sharp PA, Chakraborty AK, Young RA. 2018. Coactivator condensation at super-enhancers links phase separation and gene control. Science 361:eaar3958. doi:10.1126/science.aar3958

Schoenfelder S, Sexton T, Chakalova L, Cope NF, Horton A, Andrews S, Kurukuti S, Mitchell JA, Umlauf D, Dimitrova DS, Eskiw CH, Luo Y, Wei CL, Ruan Y, Bieker JJ, Fraser P. 2010. Preferential associations between co-regulated genes reveal a transcriptional interactome in erythroid cells. Nat Genet 42:53-61. doi:10.1038/ng.496

Socol M, Wang R, Jost D, Carrivain P, Vaillant C, Le Cam E, Dahirel V, Normand C, Bystricky K, Victor J-M, Gadal O, Bancaud A. 2019. Rouse model with transient intramolecular contacts on a timescale of seconds recapitulates folding and fluctuation of yeast chromosomes. Nucleic Acids Res 47:6195-6207. doi:10.1093/nar/gkz374

Straight AF, Belmont AS, Robinett CC, Murray AW. 1996. GFP tagging of budding yeast chromosomes reveals that protein-protein interactions can mediate sister chromatid cohesion. Curr Biol 6:1599-608. 
Taddei A, Houwe GV, Hediger F, Kalck V, Cubizolles F, Schober H, Gasser SM. 2006. Nuclear pore association confers optimal expression levels for an inducible yeast gene. Nature 441:774-8.

Taddei A, Houwe GV, Nagai S, Erb I, Nimwegen E van, Gasser SM. 2009. The functional importance of telomere clustering: global changes in gene expression result from SIR factor dispersion. Genome Res 19:611-25. doi:10.1101/gr.083881.108

Texari L, Dieppois G, Vinciguerra P, Contreras MP, Groner A, Letourneau A, Stutz F. 2013. The nuclear pore regulates GAL1 gene transcription by controlling the localization of the SUMO protease Ulp1. Mol Cell 51:807-18.

Thompson M, Haeusler RA, Good PD, Engelke DR. 2003. Nucleolar clustering of dispersed tRNA genes. Science 302:1399-401.

Toda T, Hsu JY, Linker SB, Hu L, Schafer ST, Mertens J, Jacinto FV, Hetzer MW, Gage FH. 2017. Nup153 Interacts with Sox2 to Enable Bimodal Gene Regulation and Maintenance of Neural Progenitor Cells. Cell Stem Cell 21:618-634 e7. doi:10.1016/j.stem.2017.08.012

Vallotton P, Rajoo S, Wojtynek M, Onischenko E, Kralt A, Derrer CP, Weis K. 2019. Mapping the native organization of the yeast nuclear pore complex using nuclear radial intensity measurements. Proc National Acad Sci 116:14606-14613. doi:10.1073/pnas.1903764116

Vojta T, Halladay S, Skinner S, Janušonis S, Guggenberger T, Metzler R. 2020. Reflected fractional Brownian motion in one and higher dimensions. Phys Rev E 102:032108. doi:10.1103/physreve.102.032108

Vojta T, Skinner S, Metzler R. 2019. Probability density of the fractional Langevin equation with reflecting walls. Phys Rev E 100:042142. doi:10.1103/physreve.100.042142

Vosse DWV de, Wan Y, Lapetina DL, Chen WM, Chiang JH, Aitchison JD, Wozniak RW. 2013. A role for the nucleoporin Nup170p in chromatin structure and gene silencing. Cell 152:96983. doi:10.1016/j.cell.2013.01.049

Wada AHO, Vojta T. 2018. Fractional Brownian motion with a reflecting wall. Phys Rev E 97:020102. doi:10.1103/physreve.97.020102

Wang A, Kolhe JA, Gioacchini N, Baade I, Brieher WM, Peterson CL, Freeman BC. 2020. Mechanism of Long-Range Chromosome Motion Triggered by Gene Activation. Dev Cell 52:309-320.e5. doi:10.1016/j.devcel.2019.12.007

Wood EJ. 1983. Molecular cloning. A laboratory manual by T Maniatis, E F Fritsch and J Sambrook. pp 545. Cold Spring Harbor Laboratory, New York. 1982. \$48 ISBN 0-87969-1360. Biochem Educ 11:82-82. doi:10.1016/0307-4412(83)90068-7

Xu M, Cook PR. 2008. Similar active genes cluster in specialized transcription factories. J Cell Biology 181:615-23. doi:10.1083/jcb.200710053 
bioRxiv preprint doi: https://doi.org/10.1101/2021.01.16.426968; this version posted January 17, 2021. The copyright holder for this preprint (which was not certified by peer review) is the author/funder, who has granted bioRxiv a license to display the preprint in perpetuity. It is made available under aCC-BY 4.0 International license.

Zenklusen D, Larson DR, Singer RH. 2008. Single-RNA counting reveals alternative modes of gene expression in yeast. Nat Struct Mol Biol 15:1263-71. 
bioRxiv preprint doi: https://doi.org/10.1101/2021.01.16.426968; this version posted January 17, 2021. The copyright holder for this preprint (which was not certified by peer review) is the author/funder, who has granted bioRxiv a license to display the preprint in perpetuity. It is made available under aCC-BY 4.0 International license.

A.

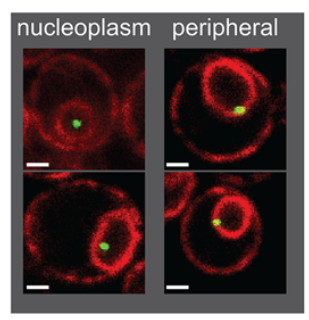

B.

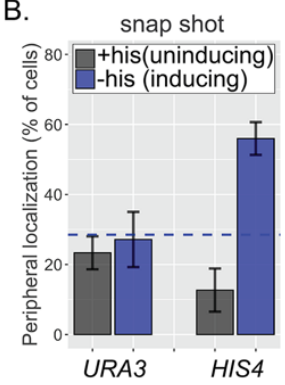

C.

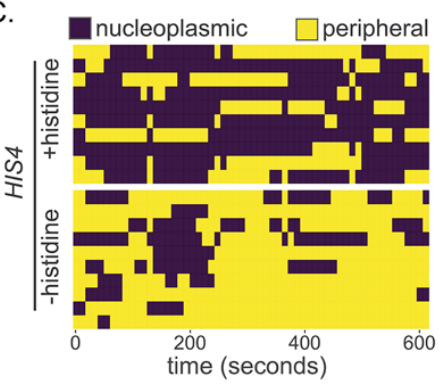

D.

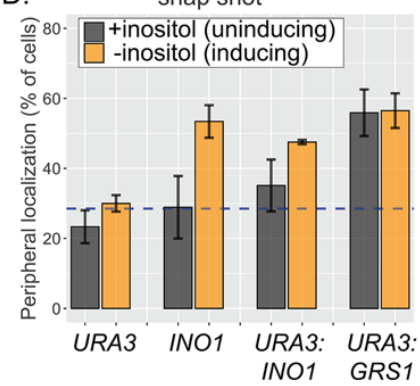

E.

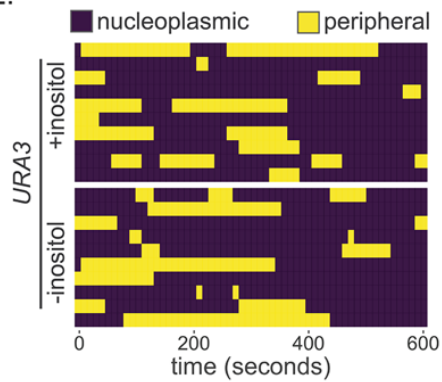

$\mathrm{H}$.

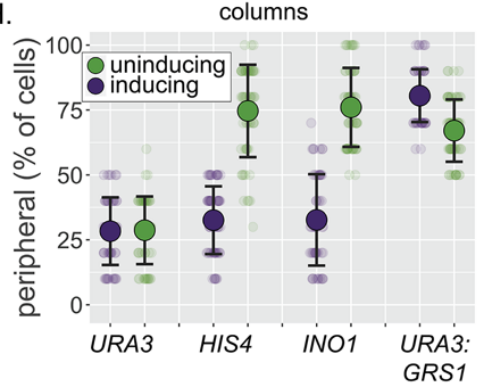

F.
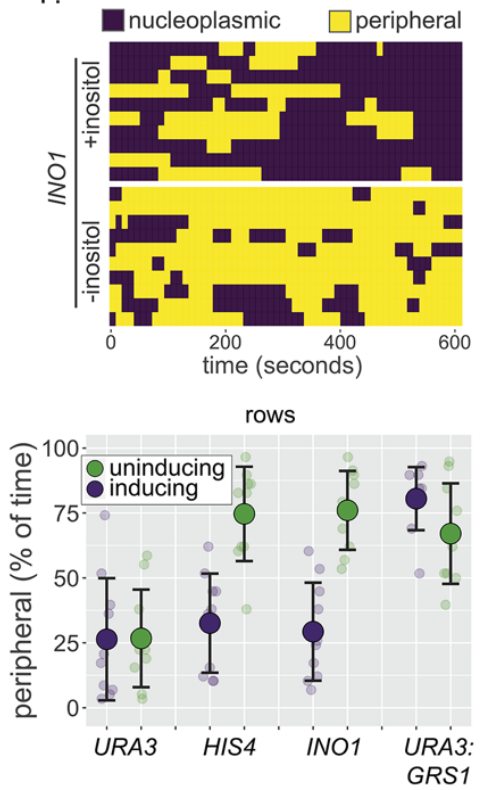

G.

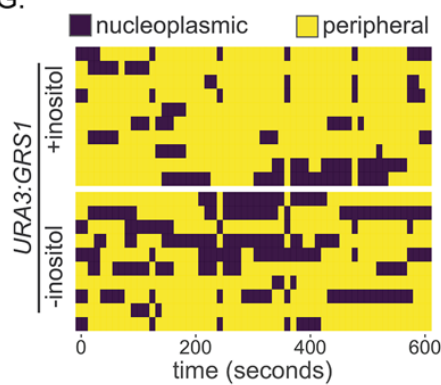

J.

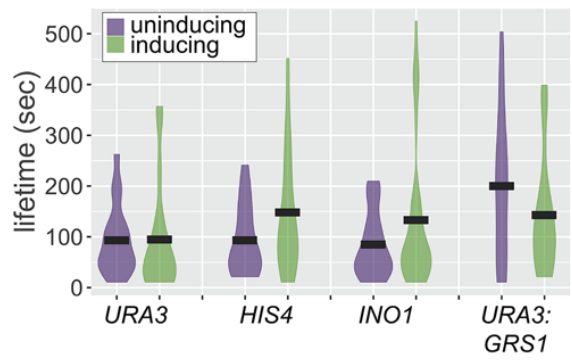

Sumner et al., Figure 1 
bioRxiv preprint doi: https://doi.org/10.1101/2021.01.16.426968; this version posted January 17, 2021. The copyright holder for this preprint (which was not certified by peer review) is the author/funder, who has granted bioRxiv a license to display the preprint in perpetuity. It is made available under aCC-BY 4.0 International license.
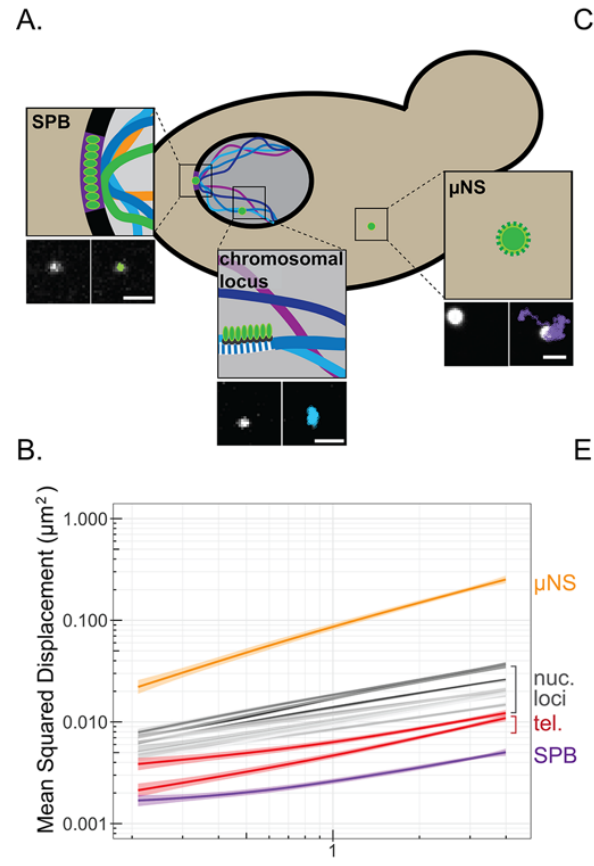

time interval (s)
C.

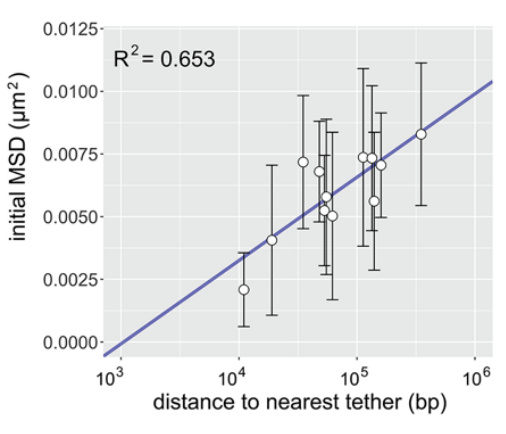

E.

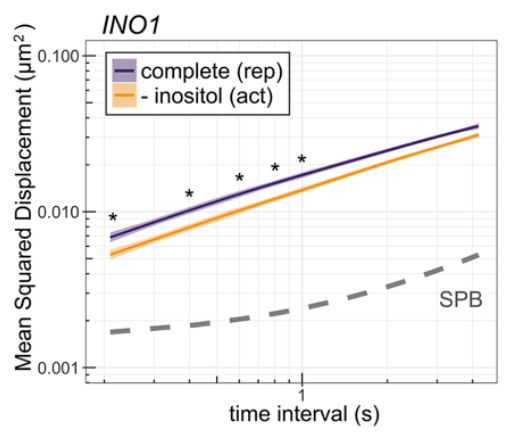

D.

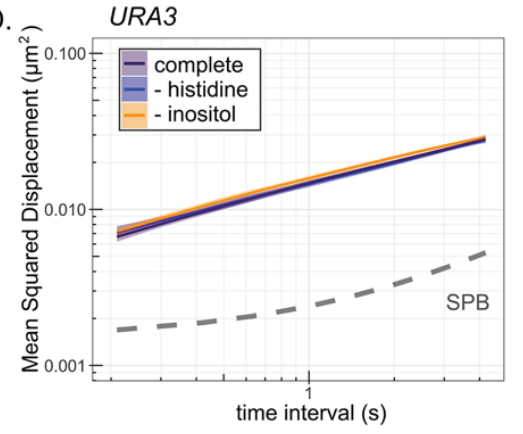

F.

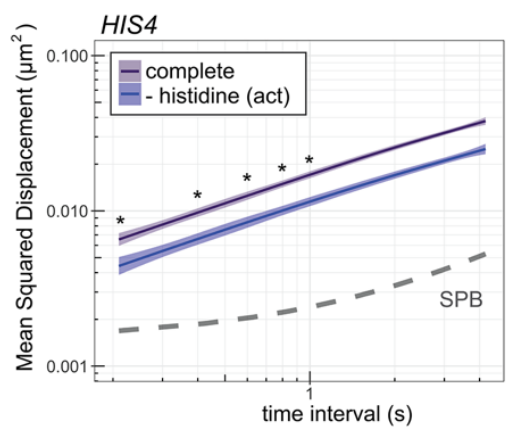

Sumner et al., Figure 2 
A.

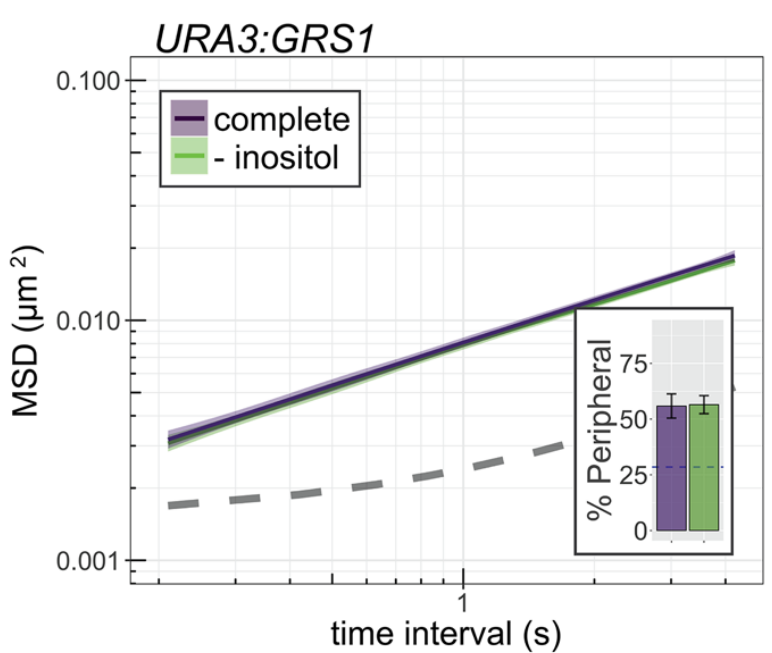

C.

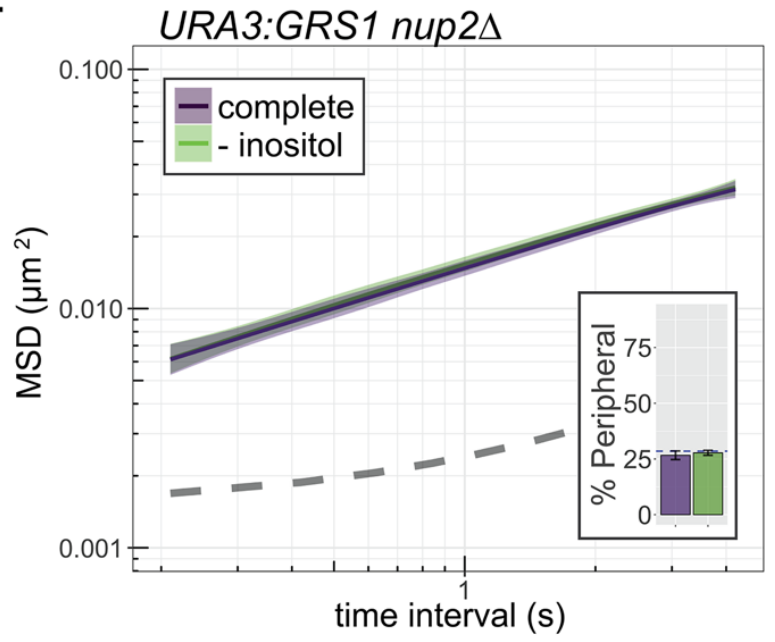

E.

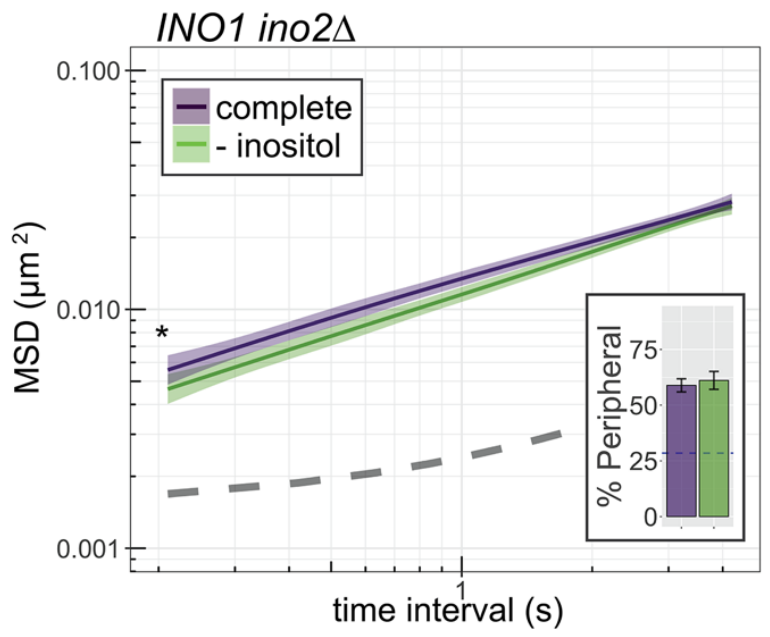

B.

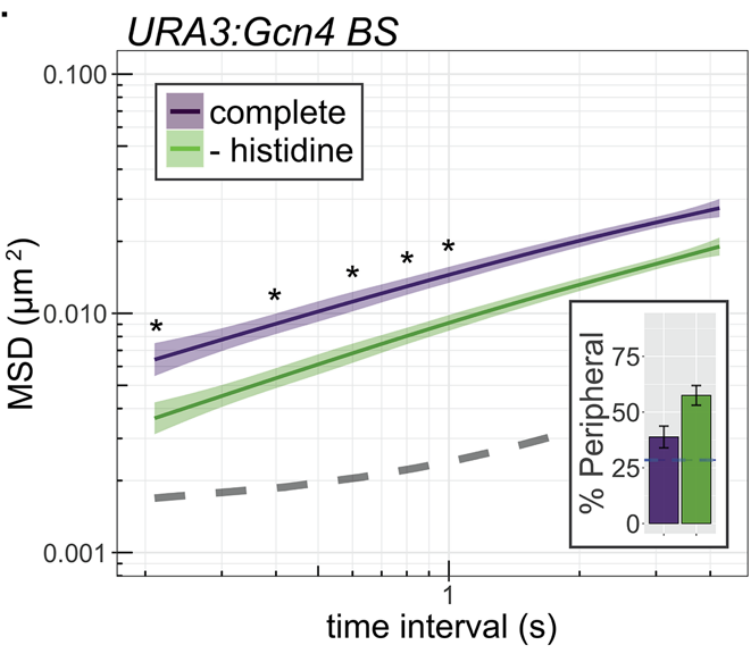

D.

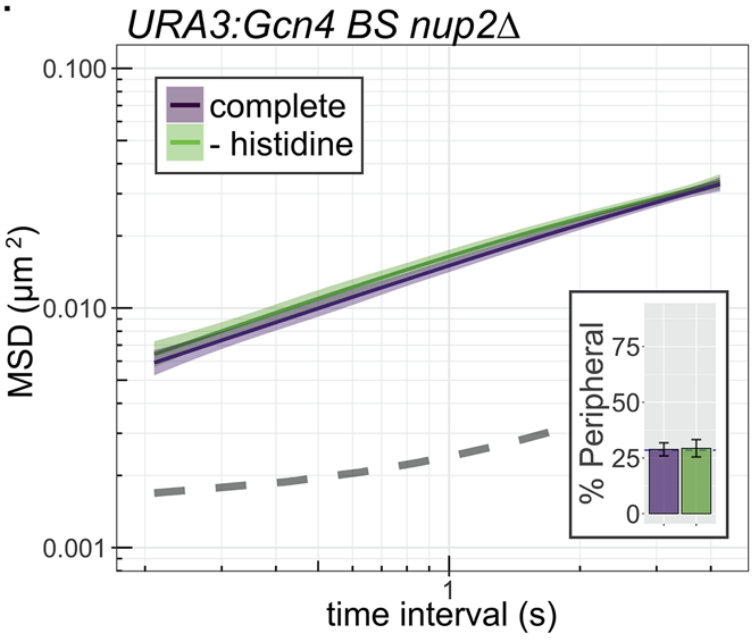

$\mathrm{F}$.

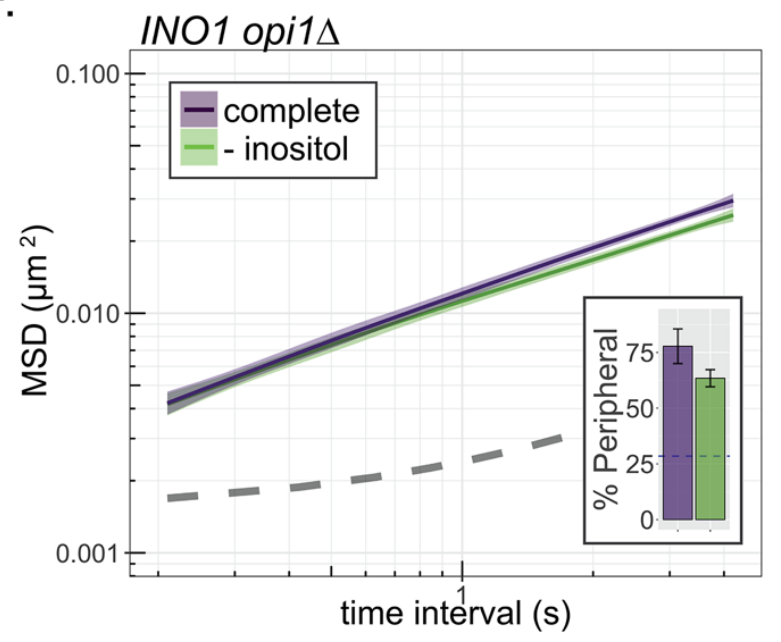

Sumner et al., Figure 3 
bioRxiv preprint doi: https://doi.org/10.1101/2021.01.16.426968; this version posted January 17, 2021. The copyright holder for this preprint (which was not certified by peer review) is the author/funder, who has granted bioRxiv a license to display the preprint in perpetuity. It is made available under aCC-BY 4.0 International license.

A.

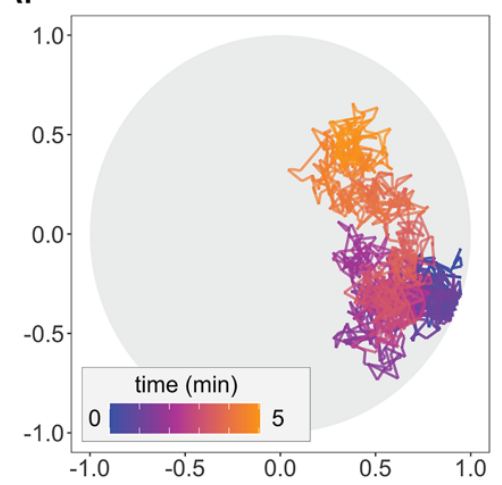

C.

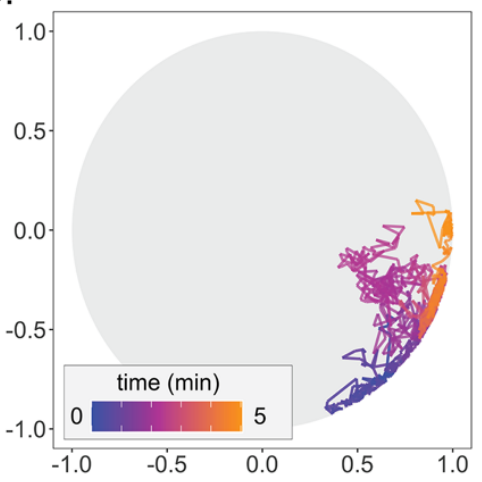

E.
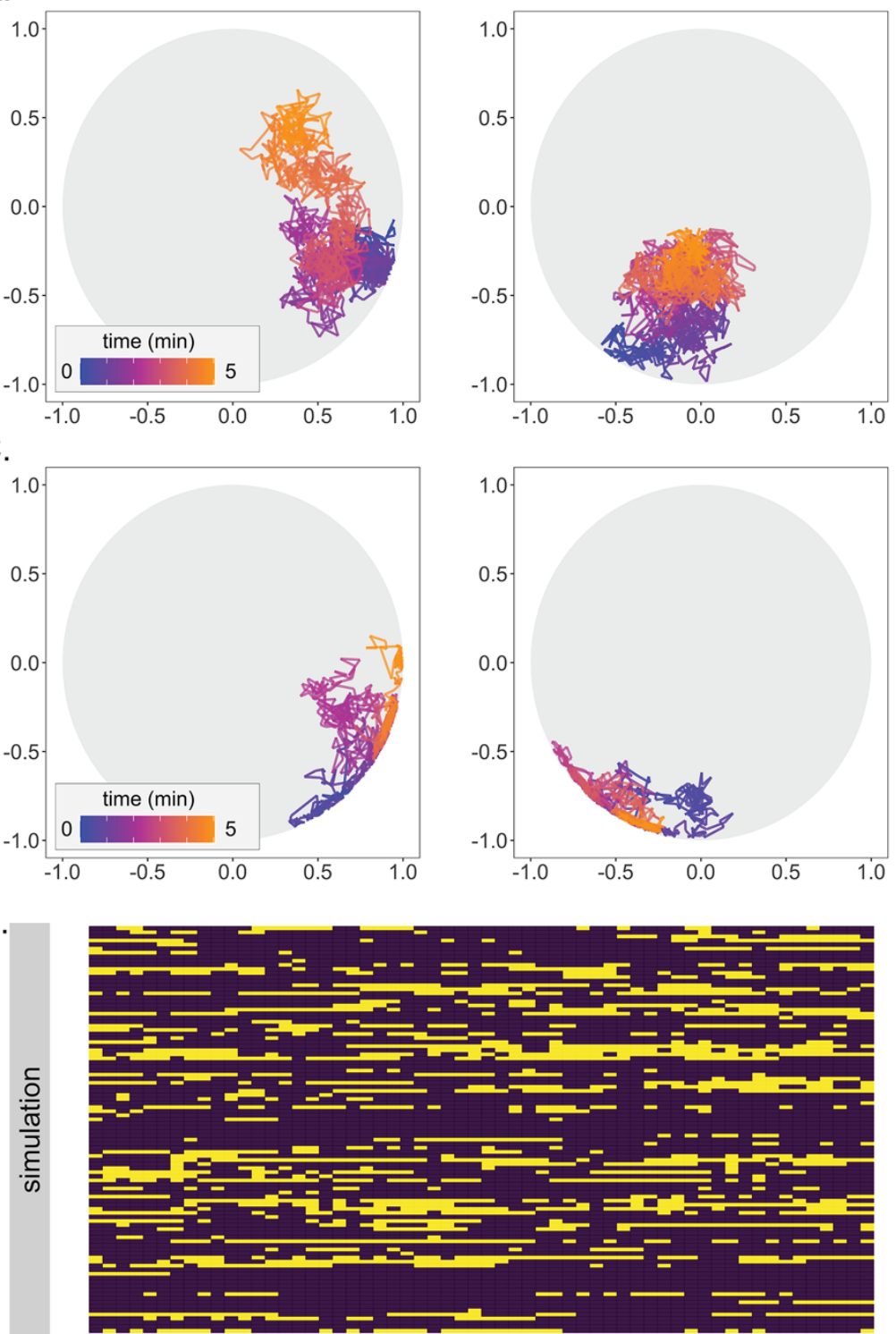

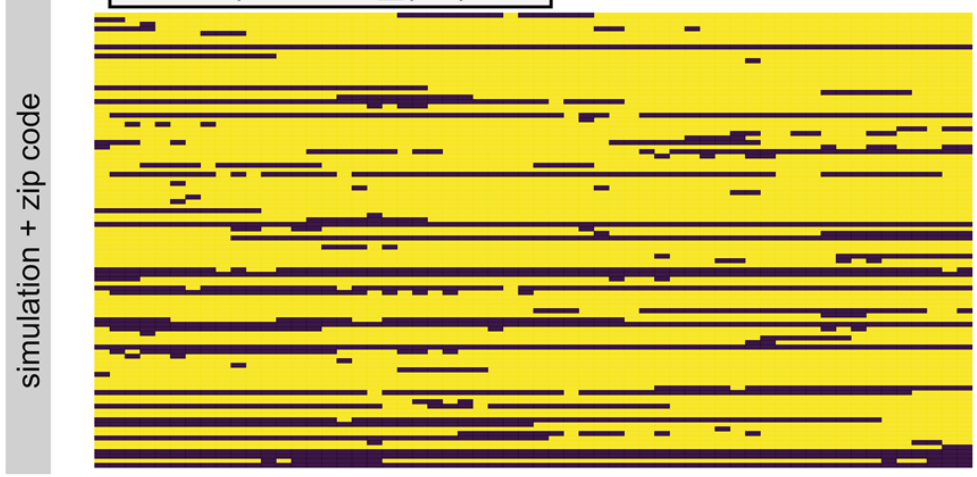

$\mathrm{F}$.

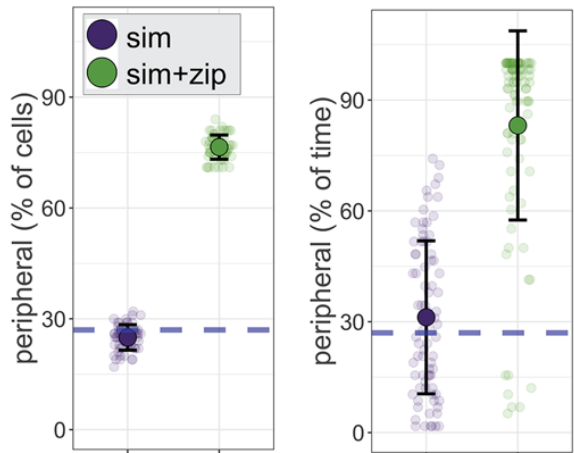

G.

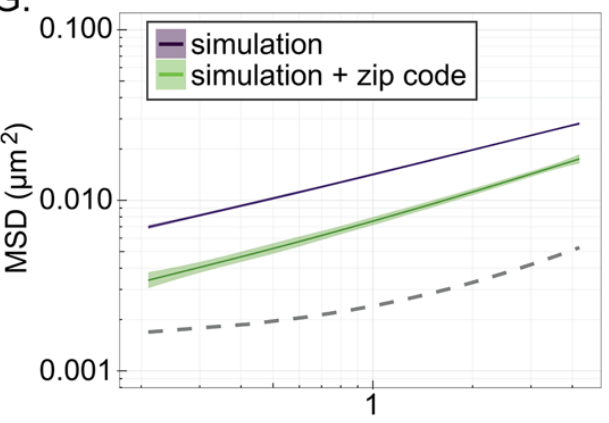

time interval (s)

Sumner et al., Figure 4 
bioRxiv preprint doi: https://doi.org/10.1101/2021.01.16.426968; this version posted January 17,2021 . The copyright holder for this preprint (which was not certified by peer review) is the author/funder, who has granted bioRxiv a license to display the preprint in perpetuity. It is made available under aCC-BY 4.0 International license.

A

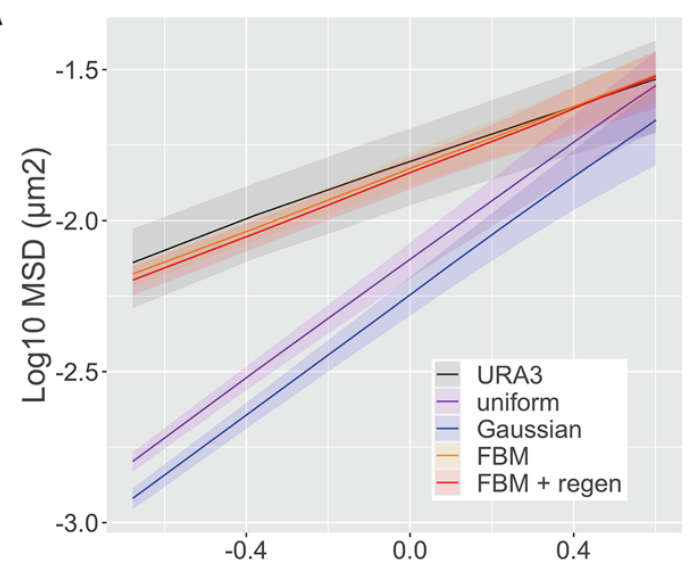

B

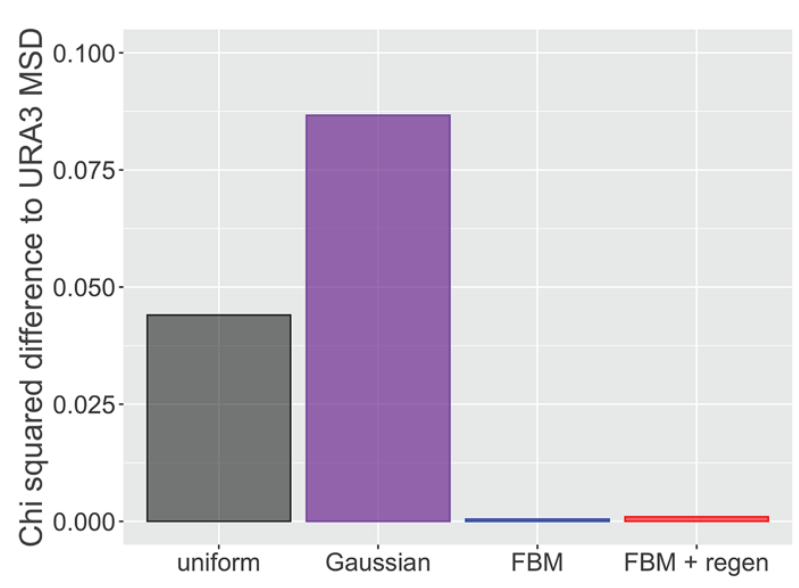

C
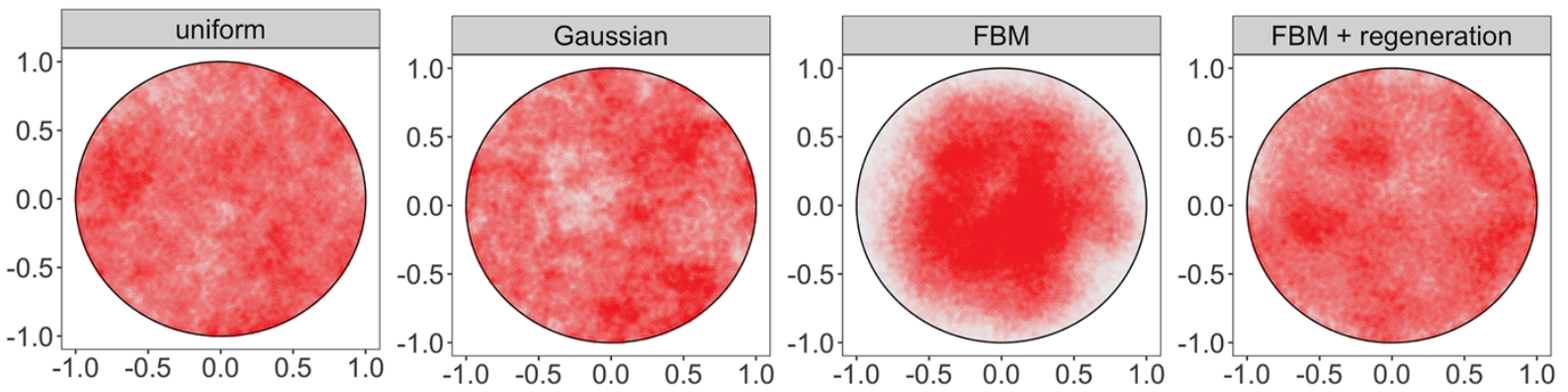

D

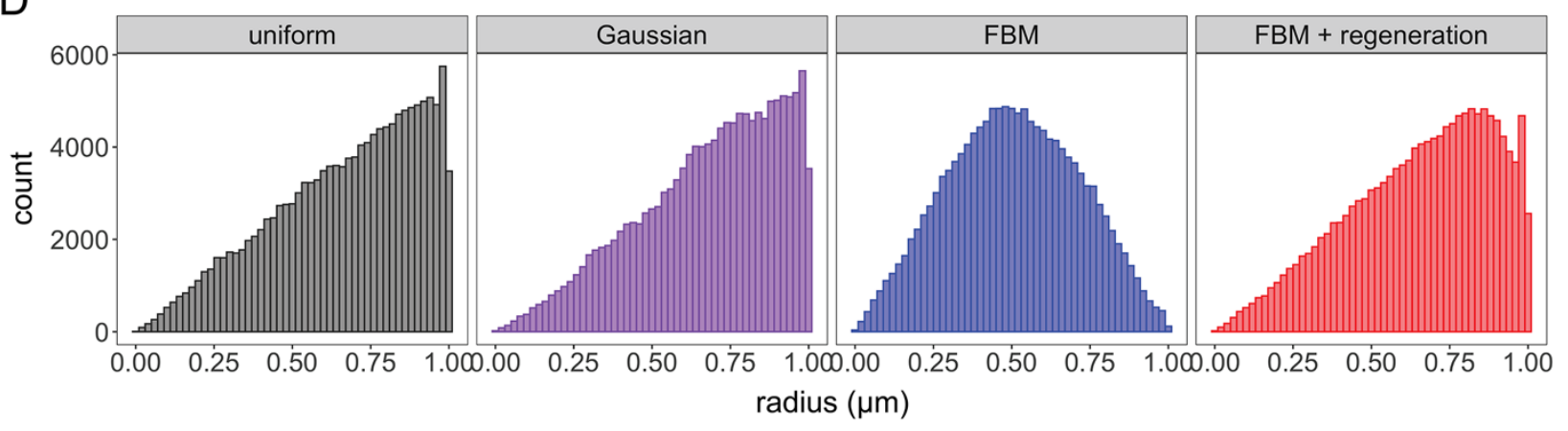

Sumner et al., Figure 4 Supplement 1 
bioRxiv preprint doi: https://doi.org/10.1101/2021 01.16.426968; this version posted January 17,2021. The copyright holder for this preprint (which was not certified by peer review) is the author/funder, who has granted bioRxiv a license to display the preprint in perpetuity. It is made available under aCC-BY 4.0 International license.

A.

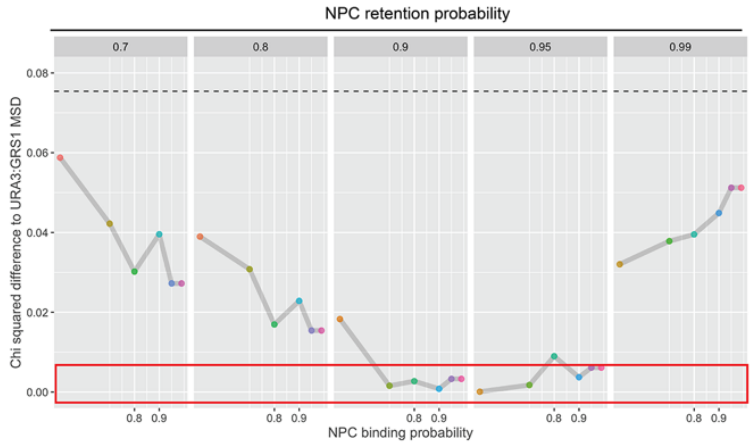

C.

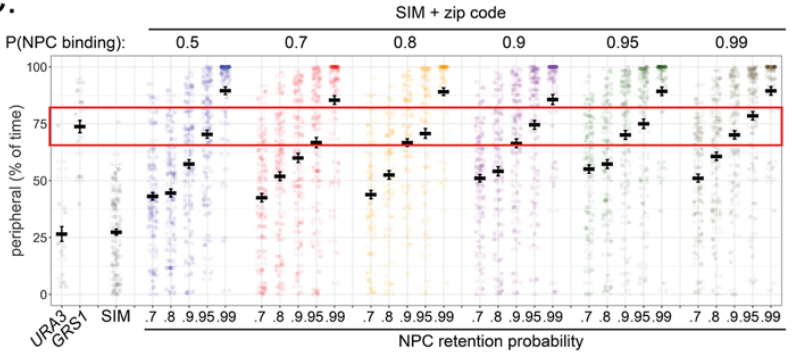

E.

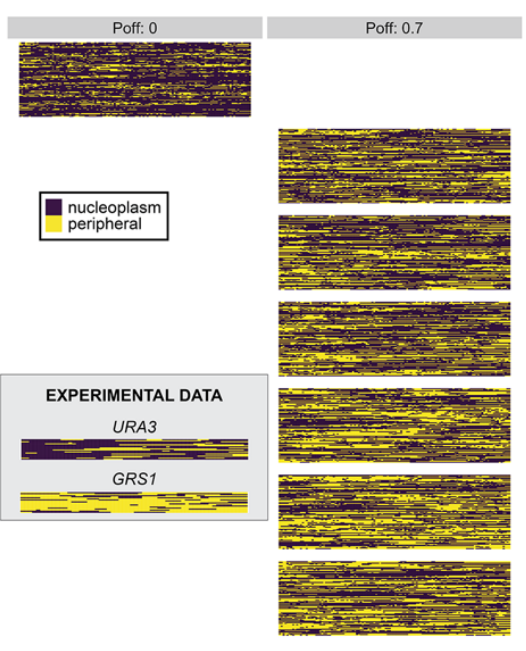

B.

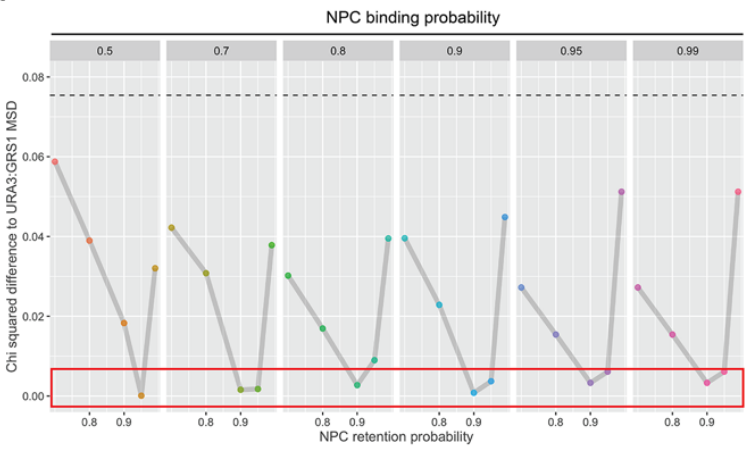

D.

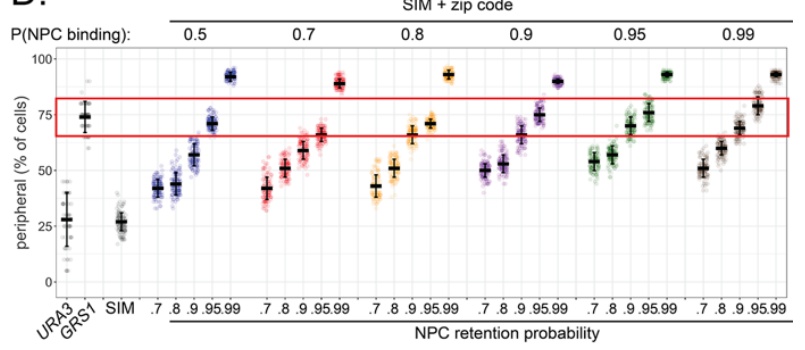

Sumner et al., Figure 4-Supplement 2 
bioRxiv preprint doi: https://doi.org/10.1101/2021.01.16.426968; this version posted January 17, 2021. The copyright holder for this preprint (which was not certified by peer review) is the author/funder, who has granted bioRxiv a license to display the preprint in perpetuity. It is made available under aCC-BY 4.0 International license.

A.

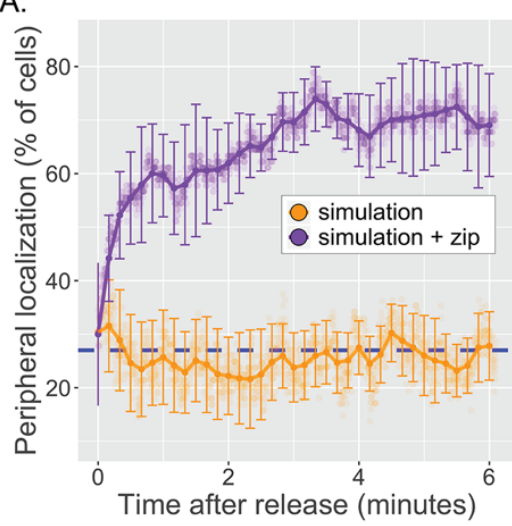

D.

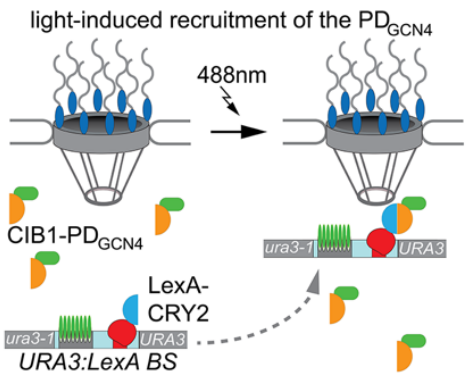

G.

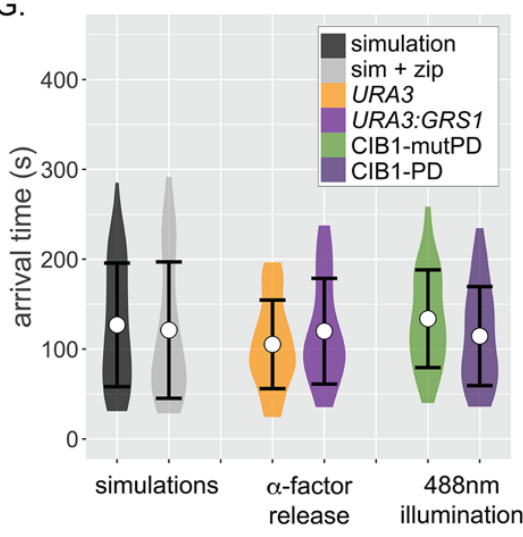

B.

peripheral relocalization after $\alpha$-factor release
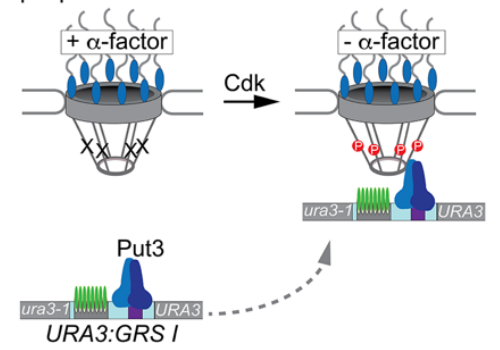

E.

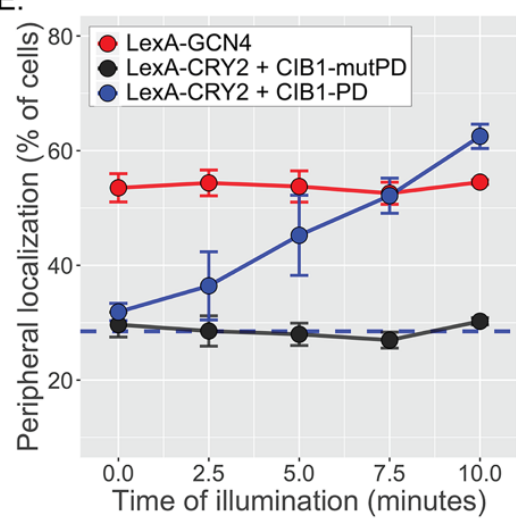

H.

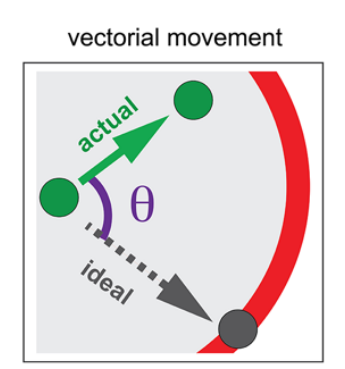

Sumner et al., Figure 5
C.

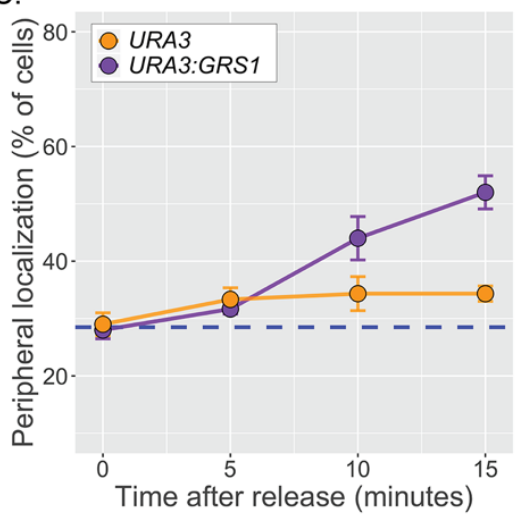

F.

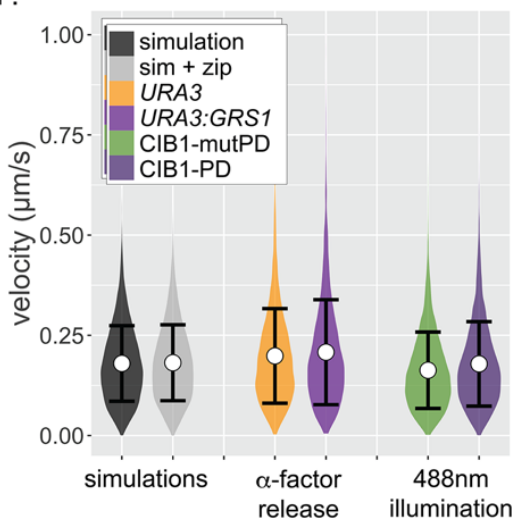

I.

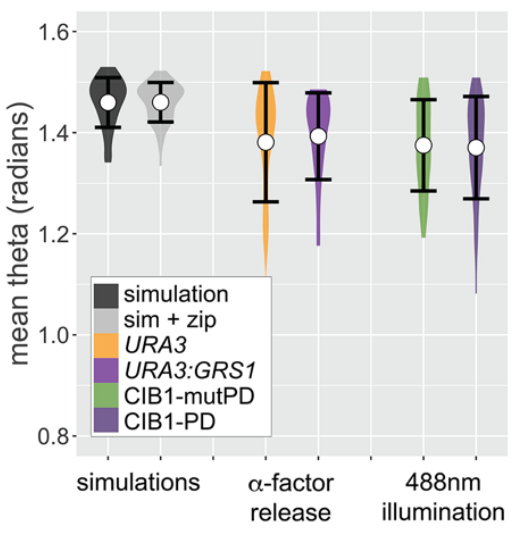


bioRxiv preprint doi: https://doi.org/10.1101/2021.01.16.426968; this version posted January 17, 2021. The copyright holder for this preprint (which was not certified by peer review) is the author/funder, who has granted bioRxiv a license to display the preprint in perpetuity. It is made available under aCC-BY 4.0 International license.

A.

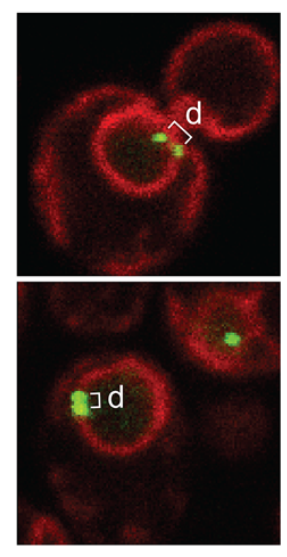

C.

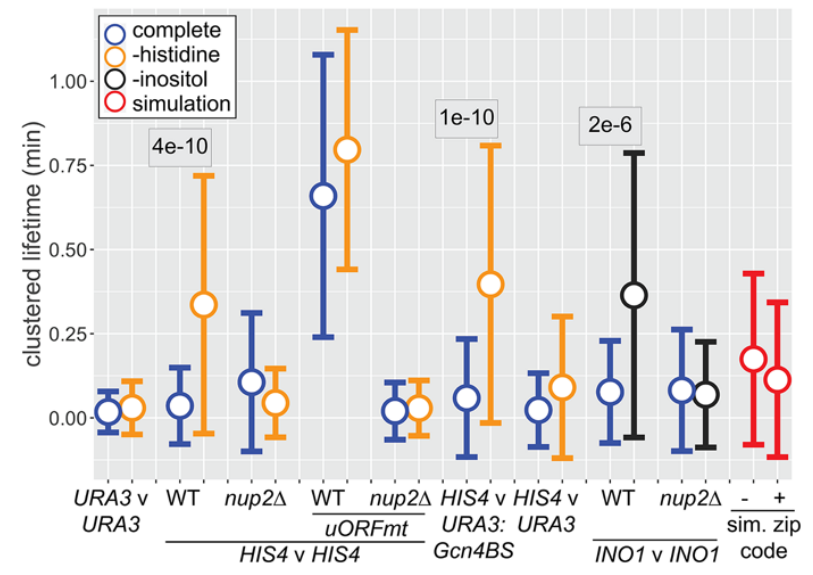

B.

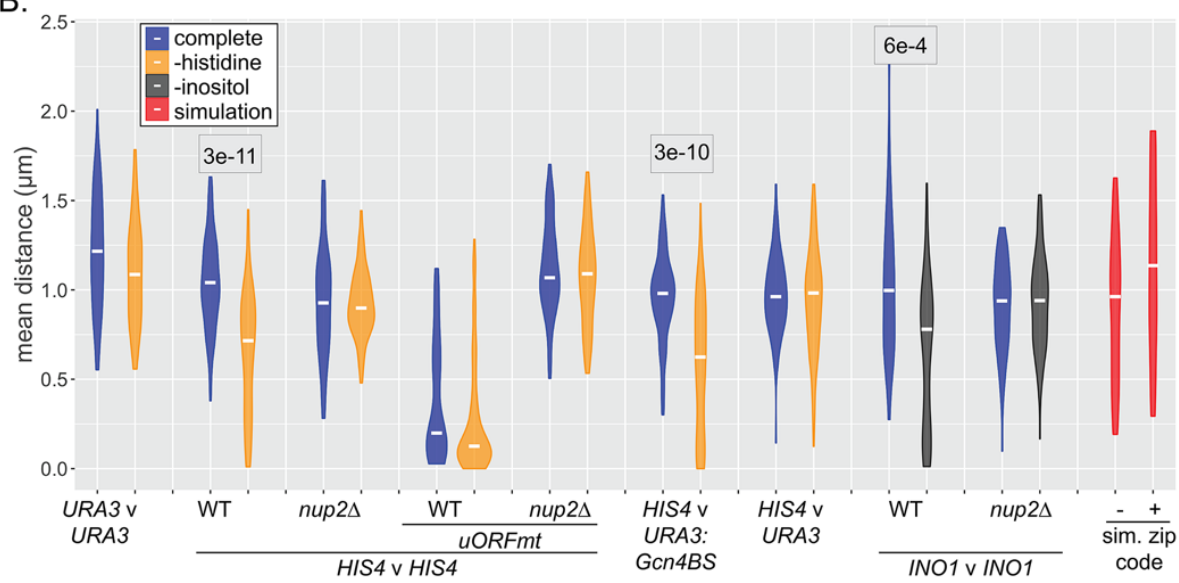

D.

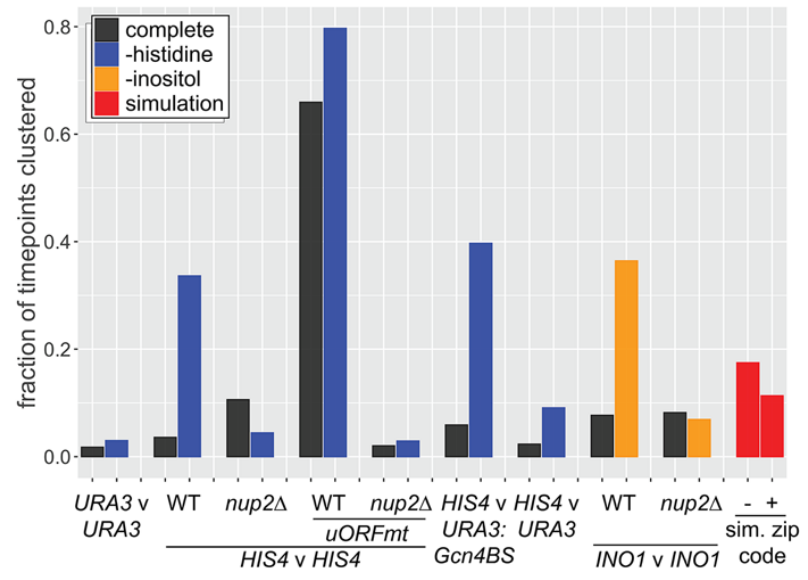

Sumner et al., Figure 6 
bioRxiv preprint doi: https://doi.org/10.1101/2021.01.16.426968; this version posted January 17, 2021. The copyright holder for this preprint (which was not certified by peer review) is the author/funder, who has granted bioRxiv a license to display the preprint in perpetuity. It is made available under aCC-BY 4.0 International license.

A.
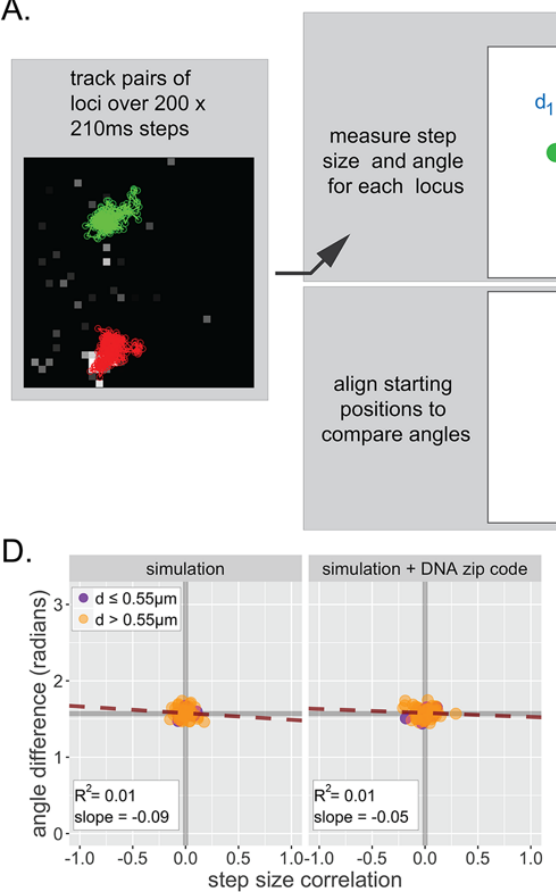

D.

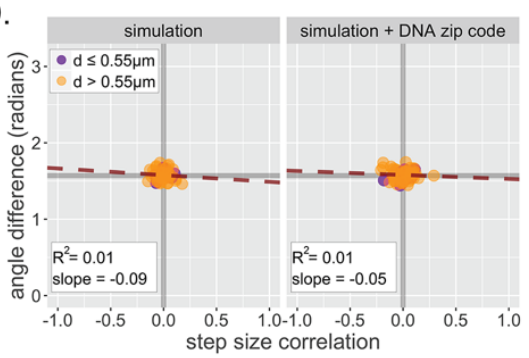

G.

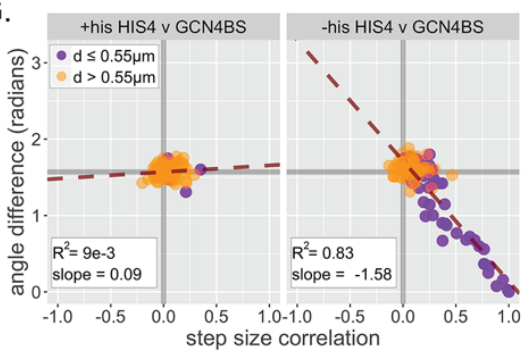

J.

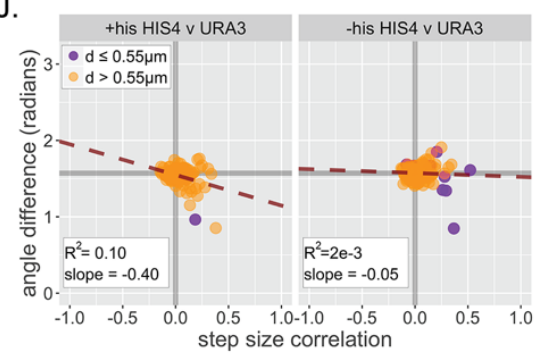

step 1
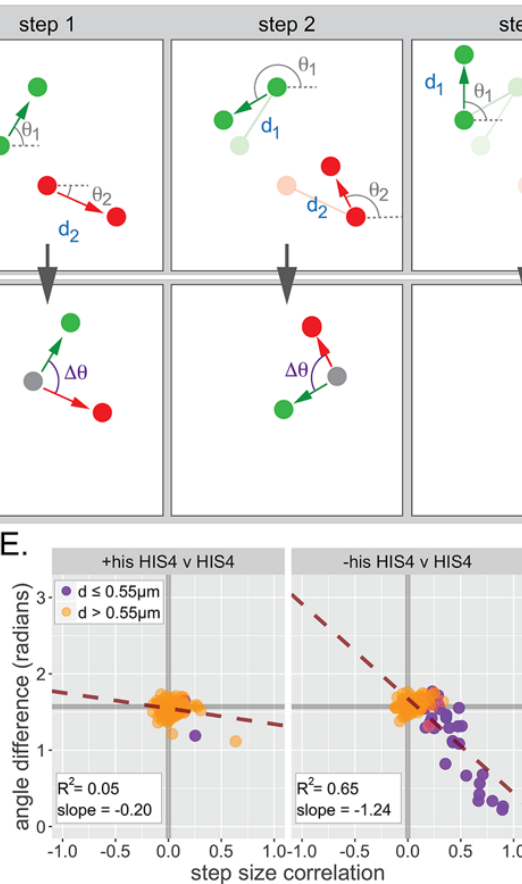

H.

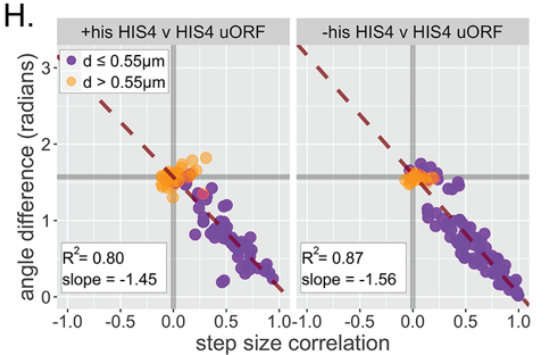

K.

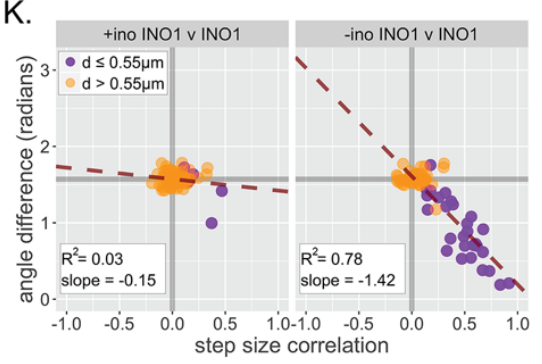

B.

\begin{tabular}{|c|c|c|c|}
\hline \begin{tabular}{|c|} 
step \\
1 \\
2 \\
3
\end{tabular} & $\begin{array}{c}\mathrm{d}_{1} \\
0.05 \\
0.16 \\
0.08\end{array}$ & $\begin{array}{c}\mathrm{d}_{2} \\
0.04 \\
0.10 \\
0.05\end{array}$ & $\begin{array}{c}\Delta \theta \\
1.57 \\
1.62 \\
0.30\end{array}$ \\
\hline \multirow[t]{3}{*}{199} & 0.09 & 0.03 & 1.11 \\
\hline & & & $\overline{\text { mean }}$ \\
\hline & & & 1.54 \\
\hline
\end{tabular}

C.

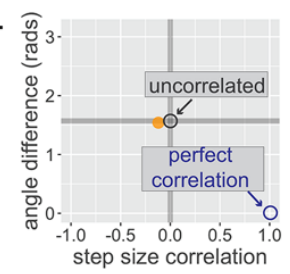

F. this HIS4 v HIS4 nup2 -his HIS4 v HIS4 nup2

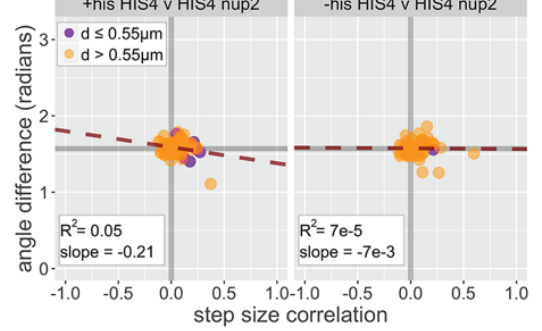

I. this HIS4 uORF nup2 -his HIS4 UORF nup2

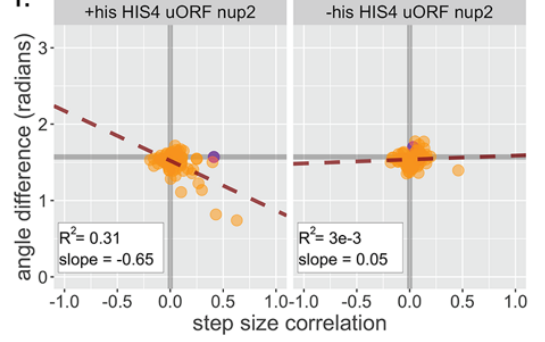

L. +ino INO1 v INO1 nup2 -ino INO1 v INO1 nup2

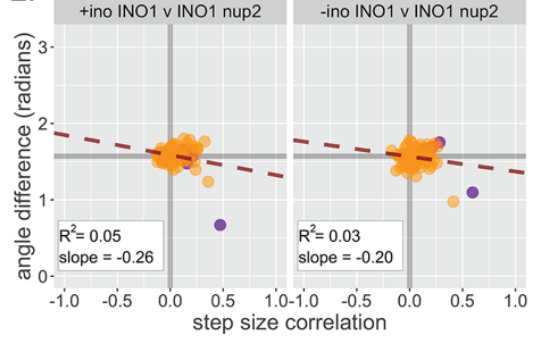

Sumner et al., Figure 7 
bioRxiv preprint doi: https://doi.org/10.1101/2021.01.16.426968; this version posted January 17, 2021. The copyright holder for this preprint (which was not certified by peer review) is the author/funder, who has granted bioRxiv a license to display the preprint in perpetuity. It is made available under aCC-BY 4.0 International license.

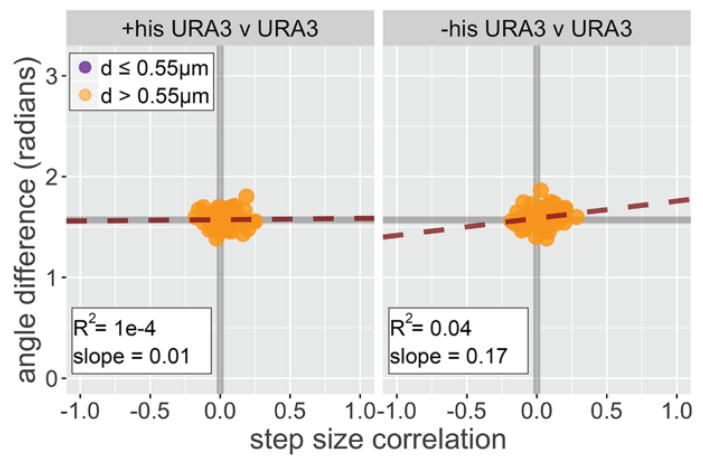

Sumner et al., Figure 7 - Figure Supplement 1 
Table S1. Mean Squared Displacement parameters ${ }^{\dagger}$

\begin{tabular}{|c|c|c|c|c|c|}
\hline Locus & Medium & Strain & $\Gamma$ & $R^{2}$ & Figure \\
\hline$U R A 3^{*}$ & SDC & WT & 0.013 & 0.998 & $2 B \& D$ \\
\hline URA3 & SDC -inositol & WT & 0.014 & 0.997 & $2 \mathrm{D}$ \\
\hline URA3 & SDC -histidine & WT & 0.016 & 0.998 & $2 \mathrm{D}$ \\
\hline HIS4 ${ }^{¥}$ & SDC & WT & 0.021 & 0.998 & $2 B \& F$ \\
\hline HIS4 & SDC -histidine & WT & 0.014 & 0.989 & $2 \mathrm{~F}$ \\
\hline INO1* & SDC & WT & 0.017 & 0.997 & $2 B \& E$ \\
\hline INO1 & SDC -inositol & WT & 0.015 & 0.963 & $2 \mathrm{E}$ \\
\hline INO1 & SDC & ino2 & 0.016 & 0.991 & $3 \mathrm{E}$ \\
\hline INO1 & SDC -inositol & ino2 & 0.017 & 0.994 & $3 \mathrm{E}$ \\
\hline INO1 & SDC & opi1 & 0.018 & 0.999 & $3 F$ \\
\hline INO1 & SDC -inositol & opi1 & 0.018 & 0.983 & $3 F$ \\
\hline URA3:GRS1 & SDC & WT & 0.009 & 0.987 & $3 A$ \\
\hline URA3:GRS1 & SDC -inositol & WT & 0.010 & 0.998 & $3 A$ \\
\hline URA3:GRS1 & SDC & nup2 & 0.019 & 0.997 & $3 C$ \\
\hline URA3:GRS1 & SDC -inositol & nup2 & 0.016 & 0.997 & $3 C$ \\
\hline URA3:Gcn4BS & SDC & WT & 0.018 & 0.992 & $3 B$ \\
\hline URA3:Gcn4BS & SDC -histidine & WT & 0.013 & 0.999 & $3 B$ \\
\hline URA3:Gcn4BS & SDC & nup2 & 0.018 & 0.999 & $3 D$ \\
\hline URA3:Gcn4BS & SDC -histidine & nup2 & 0.017 & 0.964 & $3 D$ \\
\hline INO1 (3D acq.) & SDC & WT & 0.017 & 0.998 & * \\
\hline INO1 (3D acq.) & SDC -inositol & WT & 0.015 & 0.967 & * \\
\hline$T S A 2^{\#}$ & SDC & WT & 0.011 & 0.992 & $2 B$ \\
\hline$G A L 2^{\#}$ & SDC & WT & 0.012 & 0.993 & $2 B$ \\
\hline HIS1 $1^{¥}$ & SDC & WT & 0.013 & 0.992 & $2 B$ \\
\hline$H_{I S 2^{*}}$ & SDC & WT & 0.013 & 0.996 & $2 B$ \\
\hline$H I S 5^{*}$ & SDC & WT & 0.011 & 0.992 & 2B \\
\hline HSP104 & SDC & WT & 0.015 & 0.985 & $2 B$ \\
\hline$G A L 1^{¥}$ & SDC & WT & 0.011 & 0.993 & $2 B$ \\
\hline TeloVIIIL & SDC & WT & 0.009 & 0.999 & $2 B$ \\
\hline TeloXIVL & SDC & WT & 0.009 & 0.996 & $2 B$ \\
\hline
\end{tabular}

${ }^{\dagger}$ from non-linear fit to $\operatorname{MSD}(\tau)=\Gamma(\tau)^{0.52}$

${ }^{*}$ nucleoplasmic loci from Figure $2 B$ 
Table S2. Strains used in this study

\begin{tabular}{|c|c|c|}
\hline Strain & Figures & Genotype \\
\hline NDY02 & 1B,D,E,H-J; 2D; 5C,F,G,I & $\begin{array}{l}\text { MATa can1-100 leu2-3,112 ura3-1 HIS3:Lacl- } \\
\text { GFP TRP1:pER04 LacO:URA3 }\end{array}$ \\
\hline NDY03 & 1D,F,H-J; $2 \mathrm{E}$ & $\begin{array}{l}\text { MATa can1-100 leu2-3,112 ura3-1 HIS3:Lacl- } \\
\text { GFP TRP1:pER04 INO1:p6Lac0128 }\end{array}$ \\
\hline NDY05 & 1D & $\begin{array}{l}\text { MATa can1-100 leu2-3,112 ura3-1 HIS3:Lacl- } \\
\text { GFP TRP1:pER04 INO1:p6Lac0128 }\end{array}$ \\
\hline NDY07 & 1D,G-J; 3A; 5C,F,G,I & $\begin{array}{l}\text { MATa can1-100 leu2-3,112 ura3-1 HIS3:Lacl- } \\
\text { GFP TRP1:pER04 URA3:p6Lac0120-GRSI }\end{array}$ \\
\hline CEY147 & $3 B$ & $\begin{array}{l}\text { MATa ade2-1 can1-100 his3-11,15 TRP1:pER04 } \\
\text { LEU2:Lacl-GFP URA3:p6Lac0128-GCN4BS }\end{array}$ \\
\hline DBY1840 & $3 \mathrm{D}$ & $\begin{array}{l}\text { MATa ade2-1 can1-100 his3-11,15 TRP1:pER04 } \\
\text { LEU2:Lacl-GFP URA3:p6LacO128-GCN4BS } \\
\text { nup2-cr }\end{array}$ \\
\hline CEY076 & 1B,C,H-J; $2 \mathrm{~F}$ & $\begin{array}{l}\text { MATa ade2-1 can1-100 his3-11,15 ura3-1 } \\
\text { TRP1:pER04 LEU2:Lacl-GFP HIS4:p6LacO128 }\end{array}$ \\
\hline ASY212 & $2 B \& C$ & $\begin{array}{l}\text { MATa ade2-1 can1-100 his3-11,15 leu2-3,112 } \\
\text { trp1-1, TRP1: ER04, LEU: EGFP-Lacl, } \\
\text { HIS5:p6Lac0128 }\end{array}$ \\
\hline MSY023 & $2 \mathrm{~B} \& \mathrm{C}$ & $\begin{array}{l}\text { MATa ade2-1 can1-100 his3-11,15 leu2-3,112 } \\
\text { trp1-1 ura3-1 LEU2:pAG415GPD-EGFP- } \mu N S\end{array}$ \\
\hline DBY471 & $2 \mathrm{~B} \& \mathrm{C}$ & $\begin{array}{l}\text { MATa ade2-1 can1-100 his3-11,15 leu2-3,112 } \\
\text { trp1-1 ura3-1 LEU2:Lacl-GFP SPC29-RFP:Hyg }\end{array}$ \\
\hline DBY475 & $2 \mathrm{~B} \& \mathrm{C}$ & $\begin{array}{l}\text { MATa ade2-1 can1-100 his3-11,15 leu2-3,112 } \\
\text { trp1-1 ura3-1 LEU2:Lacl-GFP SPC29-RFP:Hyg } \\
\text { HSP104:pFS2913 }\end{array}$ \\
\hline DBY477 & $2 B \& C$ & $\begin{array}{l}\text { MATa ade2-1 can1-100 his3-11,15 leu2-3,112 } \\
\text { trp1-1 LEU2:Lacl-GFP SPC29-RFP:Hyg } \\
\text { URA3:p6Lac0128 }\end{array}$ \\
\hline DBY479 & $2 B \& C$ & $\begin{array}{l}\text { MATa ade2-1 can1-100 his3-11,15 leu2-3,112 } \\
\text { trp1-1 ura3-1 LEU2:Lacl-GFP SPC29-RFP:Hyg } \\
\text { GAL1:p6Lac0128 }\end{array}$ \\
\hline JBY499 & $3 C$ & $\begin{array}{l}\text { MATa ade2-1 can1-100 leu2-3,112 trp1-1 } \\
\text { URA3:p6Lac0128 HIS3:Lacl-GFP nup2A::KanMX }\end{array}$ \\
\hline CEY391 & $5 \mathrm{E}$ & $\begin{array}{l}\text { MATa/MAT } \alpha \text { ade2-1/ADE2:pGAL1-GCN4PD- } \\
\text { LexA can1-100 his3-11,15/HIS3:Lacl-GFP leu2- } \\
\text { 3,112/LEU2:pGPDmCherry-ER05 trp1-1/trp1-1 } \\
\text { URA3:p6LacO128- } \\
\text { LexABS:KanMX/URA3:p6LacO128- } \\
\text { LexABS:KanMX }\end{array}$ \\
\hline
\end{tabular}




\begin{tabular}{|c|c|c|}
\hline MSY027 & $5 E-G, I$ & $\begin{array}{l}\text { MATa/MAT } \alpha \text { ade2-1/ade2-1 can1-100/can1-100 } \\
\text { his3-11,15/HIS3:Lacl-GFP,15 LEU2:CIB1- } \\
\text { Gcn4PD/LEU2:Pho88-mCherry TRP1:CRY2- } \\
\text { LexADBD/trp1-1 ura3-1/URA3:p6LacO } \\
\text { KanMX:LexABS }\end{array}$ \\
\hline MSY028 & $5 E-G, I$ & $\begin{array}{l}\text { MATa/MAT } \alpha \text { ade2-1/ade2-1 can1-100/can1-100 } \\
\text { his3-11,15/HIS3:Lacl-GFP,15 LEU2:CIB1- } \\
\text { Gcn4mutPD/LEU2:Pho88-mCherry TRP1:CRY2- } \\
\text { LexADBD/trp1-1 ura3-1/URA3:p6LacO } \\
\text { KanMX:LexABS }\end{array}$ \\
\hline CEY135 & 6B-D; 7E & $\begin{array}{l}\text { MATa/MAT } \alpha \text { ade2-1/ade2-1 can1-100/can1-100 } \\
\text { his3-11,15/his3-11,15 LEU2:Lacl-GFP/leu2-3,112 } \\
\text { TRP1:pER04/trp1-1 ura3-1/ura3-1 } \\
\text { HIS4:p6LacO128/HIS4:p6Lac0128 }\end{array}$ \\
\hline CEY271 & 6B-D; 7H & $\begin{array}{l}\text { MATa/MAT } \alpha \text { ade2-1/ade2-1 can1-100/can1-100 } \\
\text { his3-11,15/his3-11,15 LEU2:Lacl-GFP/leu2-3,112 } \\
\text { TRP1:pER04/trp1-1 ura3-1/ura3-1 } \\
\text { HIS4:p6LacO128 /HIS4:p6LacO128 gcn4- } \\
\text { uORFmt/gcn4D-uORFmt }\end{array}$ \\
\hline CEY270 & 6B-D & $\begin{array}{l}\text { MATa/MAT } \alpha \text { ade2-1/ade2-1 can1-100/can1-100 } \\
\text { his3-11,15/his3-11,15 LEU2:Lacl-GFP/leu2-3,112 } \\
\text { TRP1:pER04/trp1-1 ura3-1/ura3-1 } \\
\text { HIS4:p6LacO128 /HIS4:p6LacO128 } \\
\text { gcn4A::KanMX/gcn4A::KanMX }\end{array}$ \\
\hline CEY140 & 6B-D; 7G & $\begin{array}{l}\text { MATa/MAT } \alpha \text { ade2-1/ade2-1 can1-100/can1-100 } \\
\text { his3-11,15/his3-11,15 LEU2:Lacl-GFP/leu2-3,112 } \\
\text { TRP1:pER04/trp1-1 URA3:p6LacO128- } \\
\text { GCN4BS:KanMX/ura3-1 HIS4:p6LacO128/HIS4 }\end{array}$ \\
\hline DBY598 & 6B-D; 7K & $\begin{array}{l}\text { MATa/MAT } \alpha \text { ade2-1/ade2-1 can1-100/can1-100 } \\
\text { HIS3:Lacl-GFP/his3-11,15 LEU2:Lacl-GFP/leu2- } \\
\text { 3,112 TRP1:pER04/TRP1:pER04 ura3-1/ura3-1 } \\
\text { LEU2:Lacl-GFP TRP1:pER04 } \\
\text { INO1:p6Lac0128/IN01:p6LacO128 }\end{array}$ \\
\hline MSY042 & 6B-D & $\begin{array}{l}\text { MATa/MAT } \alpha \text { ade2-1/ade2-1 can1-100/can1-100 } \\
\text { his3-11,15/his3-11,15 LEU2:Lacl-GFP/leu2-3,112 } \\
\text { TRP1:pER04/trp1-1 } \\
\text { URA3:p6Lac0128/URA3:p6Lac0128 }\end{array}$ \\
\hline MSY043 & 6B-D; 7J & $\begin{array}{l}\text { MATa/MAT } \alpha \text { ade2-1/ade2-1 can1-100/can1-100 } \\
\text { his3-11,15/his3-11,15 LEU2:Lacl-GFP/leu2-3,112 } \\
\text { TRP1:pER04/trp1-1 URA3:p6LacO128/ura3-1 } \\
\text { HIS4:p6Lac0128/HIS4 }\end{array}$ \\
\hline
\end{tabular}


bioRxiv preprint doi: https://doi.org/10.1101/2021.01.16.426968; this version posted January 17,2021 The copyright holder for this preprint (which was not certified by peer review) is the author/funder, who has granted bioRxiv a license to display the preprint in perpetuity. It is made available under aCC-BY 4.0 International license.

\begin{tabular}{|l|l|l|} 
& & $\begin{array}{l}\text { MATa ade2-1 can1-100 his3-11,15 leu2-3,112 } \\
\text { trp1-1 ura3-1 INO1:p6Lac0128 HIS3:Lacl-GFP } \\
\text { ino2A:: kanMX6 }\end{array}$ \\
\hline DAY53 & 3E & $\begin{array}{l}\text { MATa leu2-3,112 trp1-1 ura3-1 opi14::LEU2 } \\
\text { SEC63-13myc:KanMX INO1:p6LacO128 } \\
\text { His3:Lacl-GFP }\end{array}$ \\
\hline
\end{tabular}

